\title{
Line Brandt
}

\author{
Copenhagen Business School
}

\section{Metaphor and the Communicative Mind}

On the occasion of the thirtieth anniversary of the first cognitive-semantic theory of metaphor - Metaphors We Live By (1980) - this paper presents a communication-oriented perspective on the practice of metaphor analysis. Through discussion of contemporary metaphor theories, it identifies a number of unresolved issues. Among these are the notions of domains, mental spaces and binding, the unidirectionality hypothesis, the emergence problem, the significance of pragmatic context, and the philosophical status of representations. The theories discussed are conceptual metaphor theory, conceptual integration theory, the neural theory of language, the attribution model of metaphor, semiotic integration theory, and relevancetheoretic approaches to metaphor including the hybrid theory of metaphor. Comparing analyses and explanatory frameworks, the paper offers a theoretical and methodological critique of these approaches as food for thought and fuel for prospective future research projects in cognitive linguistics and beyond.

Key words: domains, emergence, force dynamics, mental spaces, metaphorical meaning, pragmatics, semantic framing.

\section{COMMUNICATIVE INTENTIONALITY: A BLEND OR A PRIMITIVE?}

The last few decades have witnessed increasing awareness of the social dimension of language ${ }^{1}$ moving away from the analytical, symbol-oriented first wave of the 'linguistic turn' toward a more usage-oriented view. This has been partly inspired by an accumulating corpus of work on shared conceptual structures underlying language and the 'cognitive turn' in the humanities, but also precipitated by linguists and philosophers in the late '50s and '60s taking an interest in what people $d o$ with language (Austin 1962, Benveniste 1966, Grice 1968, Searle 1969) - contesting theories of language that disregard its social motivations. Benveniste, a key figure in developing the concept of enunciation in linguistics - the act of addressing utterances to an addressee - dedicated parts of his 1966 book $^{2}$ to what he called the presence of man in language: directing attention to the subjectivity

\footnotetext{
${ }^{1}$ Among recent publications see for e.g. (McNeill 2005, Tomasello 2006, Zlatev et al. 2008, Gallagher 2009a [citing, among others, Thomson \& Varela 2001]). Gallagher writes (2009a: 48): '...cognition is not only pragmatically situated but also always socially situated, not simply in the sense that the world is populated with others with whom we communicate but also in the sense that this communication and interaction shape our cognitive abilities from the very beginning. They push us to realize that cognition not only is enactive but also elicited by our physical and social environment; that it not only involves a deeply embodied and temporally structured action but also is formed in an affective resonance generated by our surroundings and by others with whom we interact'. See also (Harder 2010).

Appearing in English as (Benveniste 1971).
}

Address for correspondence: Copenhagen Business School, Copenhagen, Denmark; email: cogsemlb@yahoo.com. 
inherent in - and entailed by - the way language presents itself in the form of utterances, in the uttering of sentences with the dimension of situatedness that this circumstance entails.

The commonsensical - yet somewhat theoretically novel - view of language as inherently dialogical and socially conditioned finds support outside linguistics as well, appearing in neuroscience and developmental psychology. The emergence of a 'social neuroscience' is especially noteworthy particularly the research on mirror neurons, supporting a view of human beings as fundamentally attuned to interpersonal interaction while inspiring new hypotheses on the origins of language such as the hypothesis proposed by Gallese (2007) that grounds meaning in the social experience of observed or imagined intentional action. As Gallagher has suggested (2001, 2007, 2008, 2009b), mirror neuron research may even point to a notion of the Other as more primary than the Self ${ }^{3}$ - contrary to the widely held belief, e.g. in much work on theory of mind, that the Other derives from the (primary) Self.

Psychology has similarly turned toward the development of social cognition in interactive settings, ${ }^{4}$ monitoring and assessing the intelligence and emotive responsiveness involved in turntaking interaction in studies such as. Trevarthen's (1994, 1995, 1999) observations of markedly rhythmic, vocally and gesturally implemented dialogue behaviour in pre-linguistic infants. These studies indicate attunement to the causality of communicative intentionality at a very early stage of development and evidently even earlier than attunement to physical causality. As is apparent in Trevarthen's video recordings of infant-caretaker dynamics, even babies born two months premature spontaneously engage others in interactive proto-conversation. 'The dynamic patterns of feeling in protoconversation in which the infant follows and joins in rapidly transforming expressive sequences, give the clearest evidence that each human mind is innately organized for intersubjective participation with the interests and feelings of another human mind'. (Trevarthen 1994: 230)

Trevarthen's work indicates that the very uttering of utterances - their rhythmic emission in anticipation of rhythmically unfolding turn-taking events - is developmentally prior to syntax and semantics, as well as the conceptualization and vocal actualization of words needed for speech to occur. Indeed, the referential function of language appears to be secondary to the 'enunciational' feat of addressing another person: '...the syntax of verbal expression in speech and text is derivative of, or

\footnotetext{
${ }^{3}$ This is 'intrinsic intersubjectivity' or the 'intersubjective first' position (Trevarthen 1999: 417). Meanwhile, Gallese (2005: 43) writes: 'the sharp distinction, classically drawn between the first- and third-person experience of actions, emotions, and sensations, appears to be much more blurred at the level of the subpersonal mechanisms mapping it. The gap between the two perspectives is bridged by the way the intentional relation is functionally mapped at the neural-body level. Any intentional relation can be mapped as a relation holding between a subject and an object. The mirror neural circuits described in the second part of the paper map the different intentional relations in a compressed and indeterminate fashion, which is neutral about the specific quality or identity of the agentive/subjective parameter. By means of a shared functional state realized in two different bodies that nevertheless obey the same functional rules, the "objectual other" becomes "another self "'. Conversely, one could also say that the self is 'another other'.

${ }^{4}$ See e.g. Ask Larsen's (2003) step-by-step analysis of situated sign-making interaction between congenitally deafblind children and their caretakers.
} 
built upon, a nonreferential process that regulates the changes and exchanges of motivation and feeling between subjects in all communication where cooperative awareness is being created' (Trevarthen 1994: 230). In this way, enunciation is primitive, more basic than utterances - than requests, statements of fact, or whatever else utterances may serve to convey in communication. Attunement to others is at the core of language.

The primacy of the preoccupation with semiotic exchange - the child's emission of intentional signs in anticipating the enunciation of the other - suggests that enunciation is not only central to the study of meaning but is more basic than meaning construction itself. From an ontogenetic viewpoint, it is food for thought that basic rhythmic turn-taking is mastered long before the infant starts exploring its physical environment. Given a responsive environment, communicative intentionality is an immediately expressed competency in human cognition and agency.

Insights such as these contribute to a growing pile of evidence that the intentionally motivated pragmatic domain of conversational interaction is not an abstract, 'less accessible' domain in human ontology, as assumed, e.g. by Lakoff and Johnson $(1980,1999)$ - not to mention virtually every cognitive science department around the world.

To take a representative example, in Philosophy in the Flesh, intentionality is seen as the result of the blending of two metaphors (Lakoff \& Johnson 1999: 216). The prevalent - indeed, dominant assumption is that all conceptualization is shaped by the infant's experience of its physical environment. Consequently, non-physical concepts are seen as derivative, 'building on' the conceptualization of physical primitives - e.g., 'primary metaphors' - while forming abstractions of increasing complexity.

\section{SEMANTIC DOMAINS AND THE QUESTION OF DIRECTIONALITY}

The idea that bodily experience of the physical environment is constitutive of conceptual development - to the exclusion of other forms of experience, including the experience of one's body and the bodies of others responding to gesture and touch, events of intentionality-laden agency - is tied to the 'grounding hypothesis' (Lakoff \& Turner 1989: 112-120), according to which meaning goes in the direction of concrete-to-abstract along a spectrum from physical to non-physical. A feature of contemporary notions of embodiment in cognitive linguistics (CL), it is characterized by Rohrer (2007) in terms of unidirectionality of explanation, in answering the question of what domains can serve as source domains in conceptual metaphor ( $c f$. Lakoff \& Johnson 1980).

The environment furnishing one's conceptual 'architecture' with semantic structures available for metaphorical usage is sometimes referred to as a physical and social environment - Lakoff, for one, has emphasized this on several occasions. Nevertheless, it has not been made clear what theoretical

\footnotetext{
5 See also the reference to the concept of "intentional attunement" in Gallese (2005): "[...] when the organism is confronting the intentional behavior of others, it produces a specific phenomenal state of "intentional attunement"." (p. 43).
} 
implications follow from the inclusion of social aspects of experience - and, hence, conceptualization. A prominent empirical paradigm - motivating the theoretical estimation of the directionality of metaphor - relates the study of source and target domains to the study of concepts underlying motoraction verbs like 'to grasp': e.g., '... a ball' or, metaphorically, '... an idea'. Gallese \& Lakoff (2005: 470), drawing on research in neuroscience - particularly research on the role of canonical and mirror neurons in the observation and execution of deliberate action - conclude that the concepts characterized in the sensory-motor system are of the right form to characterise the source domains of conceptual metaphors'. This may be true. ${ }^{6}$ However, so long as the methodology reveals a bias toward certain kinds of action verbs - namely, those that designate object-oriented action and perception - the inferred results will be similarly biased. The neural theory of language, as represented by Gallese and Lakoff, may be jumping the gun on the issue of grounding. The inferred assumption of only one 'right' form to characterize source domains is (logically) premature, deriving its argument from a methodologically constricted body of data.

One gets an incomplete view of language if one looks only at concrete action verbs and disregards linguistic units that designate actions defined by their mental effects and by their significance in social settings: i.e., actions that require interpretation. These include social, 'institutional' verbs like 'to vote' as well as verbs designating actions in the domain of communication: e.g., so-called speech-act verbs like 'to promise', 'to greet', 'to congratulate', etc. The potency of face-to-face communication as a source domain in metaphor is apparent in the use of speech-act verbs to express force-dynamic relations outside the domain of speech acts: i.e., when verbs like 'threaten', 'promise', or 'suggest' are applied to the weather or some other phenomenon of a non-communicational - e.g., physical or inferential - nature.

Metaphorical language use of this sort is not, of course, restricted to verbs; it employs other parts of speech: nominal, adverbial, and adjectival derivations such as a 'threatening' sky. Consider this sentence, in which the noun 'answer' conveys a perceptual experience: 'the hills humping up behind the beach were a shrill green hue, vivid and outrageous, an angry answer to all of that gray water that lay before them'. ${ }^{7}$ Note the metaphorical description of the hills as an 'angry answer' to the tepid water. Such metaphors illustrate that the direction from source to target domain can go from nonphysical to physical, calling into question the empiricist assumption that the semantic domain of

\footnotetext{
${ }^{6}$ Willems and colleagues (2009) criticize the neurolinguistic claim that semantics is all about motor neurons, based on results showing neural dissociations between action-verb understanding and motor imagery. The authors used $\mathrm{fMRI}$ to test whether implicit simulations of actions during language understanding involve the same cortical motor regions as explicit motor imagery. They found that the primary motor cortex showed effector-specific activation during imagery but not during lexical decision.

${ }^{7}$ The example comes from W. Tower's (2004) story 'Everything ravaged, everything burned'.
} 
communicative face-to-face interaction ( $a k a$ the speech-act domain: Sweetser $1990^{8}$ ) reduces to a host of more complex and abstract concepts derived from physical experience. ${ }^{9}$

Similarly, the verb 'to interrupt' can address one's field of vision - one's view may be interrupted by trees, statues, or billboards; or maybe one cannot enjoy the view 'thanks to' certain obstructions. Going in the same direction from the domain of communicative interaction to the physical domain, the verb 'to disagree' can be used to talk about digestion: a meal may 'disagree' with someone.

At the more sophisticated end of human experience, a painting or piece of music may 'speak' to someone. Saying and telling are likewise commonly used to signify that something is indicated: e.g., 'what does that tell you?' Such metaphors go from the domain of face-to-face interaction to the mental domain of making inferences: the epistemic domain (Sweetser 1990). ${ }^{10}$ Sweetser offers an etymological example of semantic drift that does not comply with the unidirectionality rule: the French word for 'listen'/'hear': entendre, belonging to the physical domain, which originally denoted intentionality. This and similar observations manifest a propensity for non-physical domains to act as source domains in conceptual and expressive constructions of metaphorical meaning, 'speaking' against the unidirectionality hypothesis by which all meaning is rooted in the physical domain.

That face-to-face communication is a prolific semantic resource is evident in a variety of ways. Brandt (2013) offers an extensive argument, based on wide and varied empirical observation of language use, for the significance of the basic pragmatic condition of verbal interaction $(c f$. the linguistic notion of enunciation) as a factor in language at every level of complexity, and the inclusion of the utterance as a structural element in semantic analysis, e.g. in the analysis of metaphors. One line of evidence comes from Pascual's introduction, into CL, of the novel notion of fictive interaction (2002; see also 2006, 2008; Brandt 2008, 2010, 2013): a linguistic phenomenon exposing the

\footnotetext{
${ }^{8}$ For Sweetser (1990), this is both a metalinguistic and a speech-act domain.

One has yet to see any step-by-step description of how abstract concepts derive from physical primitives: e.g., how the concept of someone answering someone might plausibly originate in experience of concrete physical circumstances and, thus, how concepts requiring an understanding of intentionality derive from experience of non-intentional aspects of reality. 10

The difference in domain types helps explain the polysemous use of certain linguistic units: e.g., why the modal verb in 'that can't be right' (epistemic force) means something different than it does in 'you can't park here' (social force) or 'the dam can't hold the water back' (physical force). Sweetser's work on modality takes inspiration from Talmy's (2000) force-dynamic modeling of causation. In a chapter inspired, in part, by Talmy's approach to deontic modality and causality in terms of forces and barriers (cf. force dynamics), Sweetser sets forth (1990: 73) an 'analysis of linguistic modality as being generalized or extended from the real-world domain to the domains of reasoning and speech acts'. '...It seems evident that a modal verb may be interpreted as applying the relevant modality to: 1 . the content of the sentence: the real-world event must or may take place; 2. the epistemic entity represented by the sentence: the speaker is forced to, or (not) barred from, concluding the truth of the sentence; 3. the speech act represented by the sentence: the speaker (or people in general) is forced to, or (not) barred from, saying what the sentence says' (1990: 72-73). The polysemy between different senses appears as the conventionalization of a metaphorical mapping between the root domain of social and physical reality (the sociophysical domain), the epistemic domain, and the speech-act domain motivating metalinguistic language use: e.g. 'I must say...'. The speech-act domain is, perhaps, more accurately described as the domain of 'the act of speaking' itself: i.e., discourse (1990: 57).
} 
prominence of pragmatic experience in human cognition. ${ }^{11}$ These studies in structural aspects of situated language use demonstrate the status of verbal interaction as a resource in grammar and in mental-space blends, at the linguistic level of discourse.

Research on the role of communication / enunciation / verbal interaction as semantic resources challenges widely held beliefs in CL as well as current theories of metaphorical cognition and language use, such as:

- The primacy of the physical domain: in the empiricist tradition of contemporary cognitive science, physical experience is thought to be more concrete, more basic, and more easily accessible than other forms of experience. This belief is of import to another contemporary dogma, which I have not seen contested or critically discussed anywhere: that of the directionality of 'sense transfer' in metaphor (from the Greek meta- 'over', 'across' + pherein 'to carry', 'to bear'), from one semantic domain to another.

- The unidirectionality hypothesis: meaning flows unidirectionally from the physical domain to the domains of social activity and relations, epistemic activity such as reasoning, and communicational or metalinguistic activity. The hypothesis claims that the source domains in metaphor can be characterized as more concrete than the target domains and that, in terms of semantic domains, the direction goes from the physical domain to other, more abstract domains. Given the proposed 'upward movement' of language, from the physical to the 'spiritual' (see e.g. Urban 1939), the abstract concepts of people's social, interactional, emotional, and mental lives can be traced back to origins in sensorimotor experience of the physical environment. Though counterexamples have been documented - e.g., Lakoff \& Turner note (1989: 142) that 'it is common to speak of lines "converging" or "meeting", as if they were moving, ${ }^{12}$ - they are not recognized as counterexamples.

- The notion of domain: what does the term 'domain' refer to in CL in relation to e.g. metaphor? Considering the different usages, it is far from clear what phenomena are covered.

An example illustrates the problem: say one wants to investigate some aspect of the brain's processing of metaphor. One must first decide what counts as metaphor: i.e., what data to admit in setting up the experiments. One must choose a method for distinguishing metaphors from other kinds of phenomena. The notion of domain - e.g., experiential, semantic, and conceptual domains - is central to contemporary theories, but the task of specifying what constitutes a domain gets little or no attention. Experiments assuming Conceptual Metaphor Theory (CMT: Lakoff \& Johnson 1980, Lakoff 1987) as their theoretical base look for instances of structure being transferred from a source to a target

\footnotetext{
${ }^{11}$ The phenomenon is known as fictive (verbal) interaction in (Pascual 2002) and as generic vs. fictive verbal interaction or generic vs. fictive enunciation (i.e., two types) in (Brandt 2008, 2013) .

12

'Meeting' is a social concept and does not merely indicate movement.
} 
domain. ${ }^{13}$ The conceptual structure MORE IS UP is said to constitute one such instance. The problem is that, when one considers the source and target elements of this 'primary' metaphor, neither 'more' nor 'up' constitute experiential domains - or semantic domains for that matter; these are schemas skeletal, dynamic schemas that are potentially active in all experiential domains (e.g. those of architecture, archery, argumentation, hunting, cooking, traveling, and so on).

Conceptual confusion surrounding the notion of domain cannot be ascribed to terminology alone. If one takes some of the varied uses in the CL literature under consideration, it becomes apparent that considerable effort will be required to sort them out. One such use is found in Fauconnier's (1994 [1985], 1997) theory of mental spaces, anticipating later use in Conceptual Integration Theory (CIT: Fauconnier \& Turner 1994, 2002). It is not made clear what the notion of domains is intended to encompass; but the spaces introduced by the theory are sporadically referred to as domains.

Aside from a finite number of domains of phenomenal reality: semantic - or, as I would call them, ontological - domains ${ }^{14}$, and a non-finite number of experiential domains constituting e.g. source and target domains in conceptual metaphor), Fauconnier adds two further uses of 'domain'. 'Mental spaces are the domains that discourse builds up...' (1997: 34, emphasis added). Each space is associated with a certain domain: be it a time space, a [physical] space space, a domain space, etc. ${ }^{15}$ One thus ends up with semantic, or 'ontological', domains within which there are experiential domains feeding domains (read: mental spaces) associated with different domains (types of spaces: e.g., 'hypotheticals' or 'beliefs'). Add to this the identification of schemas as domains, ${ }^{16}$ and one is up to five different senses. If all these senses are employed at once, one gets domains specifying domains structured by domains containing content from domains grounded in domains.

\footnotetext{
The paradigm has survived into the new millennium in linguistic, literary, and computational studies around the world (see Feldman \& Narayanan 2004). Thirty years on, it has had to withstand some tweaking, not least from the founders themselves. Some of its tenets have been modified by Fauconnier \& Turner's work (2002) showing, among other things, that the transfer metaphor inherent in the concept of metaphor itself has limitations.

14

These are identified as socio-physical, epistemic and speech-act domains in (Sweetser 1990). The term 'ontological domain' is an adaptation of Sweetser's idea of 'semantic domains', which are fixed in number, as opposed to 'experiential domains' which are as numerous as the differing individual, context-dependent, historically and culturally determined framings of what exists. Ontological domains are based on cognitively universal distinctions between different phenomenal realities: e.g., physical versus social reality or social reality (work, traffic regulations, etc.) versus the intimacy and ethics of face-to-face communication (the speech-act domain). The question of what ontological (or 'semantic') domains exist is thus a question of natural ontology: a phenomenology of the world as experienced by humans. For more on 'semantic domains' in this ontological sense, see Brandt (2004: 21-67). Brandt distinguishes four basic semantic domains: natural (physical) (D1), cultural (social) (D2), mental (D3), and spiritual (speech-act) (D4); these domains combine into 'satellite domains'.

${ }^{15}$ Assume that the domains in domain spaces are experiential domains.

${ }^{16}$ Cf. Lakoff's classification of abstract, 'image-schematic' structures as experiential domains: e.g., a domain of paths, a domain of barriers, a domain of bounded regions.

${ }^{17}$ Yet another sense of domain exists in cognitive grammar (Langacker 1987): the meaning of 'thumb' or 'finger' is understood in relation to the domain 'hand': a domain evoked by the profiled element. Harder (2010:
} 


\section{METAPHORIC PREDICATES AND METAPHORIC BLENDS}

As a point of departure, all theories I discuss in this paper agree that metaphors are fundamentally a conceptual rather than linguistic phenomenon, pervasive in human cognition and language. Most take a primary interest in the conceptual rather than the expressive aspect of metaphor, ${ }^{18}$ and most agree on a basic distinction between literal and metaphorical processing. ${ }^{19}$ Talmy writes (2000:168):

The very characteristic that renders an expression metaphoric - what metaphoricity depends on - is the fact that the speaker or hearer has somewhere within his cognition a belief about the target domain contrary to his cognitive representation of what is being stated about it, and has somewhere in his cognition an understanding of the discrepancy between these two representations.

In the last ten years, some theorists have moved away from CMT, while others have made efforts to integrate elements of CMT into newer theories like Conceptual Integration Theory (CIT) or Relevance Theory (RT). ${ }^{20}$

Tendahl \& Gibbs (2008: 1837) propose a hybrid network model with five spaces, consisting of both experiential domains and mental spaces. Though stated as fact, the model must be taken as a very sketchy hypothesis that would benefit from more careful explication. The most glaring question is how it is possible for direct mapping between domains and spaces to take place, given that a (mental) space is commonly understood as '...a partial and temporary representational structure which speakers construct when thinking or talking about a perceived, imagined, past, present, or future situation. Mental spaces (or, "spaces", for short) are not equivalent to domains, but, rather, they depend on them: spaces represent particular scenarios which are structured by given domains' (Grady, Oakley \& Coulson 1999: 102, emphasis added). ${ }^{21}$

As I have demonstrated, the status of domains is uncertain. Furthermore, it is not entirely clear what spaces are ${ }^{22}$; as Hougaard (2005) points out, it is unclear what all the phenomena classified as 'spaces' have in common.

39) writes: 'from the point of view of language, a very basic question is: what precisely is the meaning of a linguistic expression? [Cognitive Linguistics] has not spent a great deal of time worrying about the question, probably because that was something truth-conditional semanticists did. The most generally accepted position is that of Langacker (1987: 161f.): while an expression evokes the whole domain, it only specifically designates the profiled subpart. The word daughter evokes the family domain, but only designates the female offspring and therefore the female offspring is the point of access to the domain. Thus an individual linguistic concept may be thought of as a "point-of-access" to something that is necessarily bigger than the concept itself'.

${ }^{18}$ Semiotic integration theory (Brandt \& Brandt 2005 [2002]; see also Pascual 2002, Hougaard 2005) is an exception .

${ }^{19}$ Relevance Theory (Sperber \& Wilson 2008) is an exception.

${ }^{20}$ See Tendahl (2009) and Brandt (2010, 2013).

${ }^{21}$ Mental spaces are 'small conceptual packets constructed as we think and talk, for purposes of local understanding or action' (Fauconnier \& Turner 2002: 40). However, these 'packets' are likewise claimed to be generated by blended spaces (Fauconnier \& Turner 1999: 3).

22

See Chapter Three in Brandt (2013) for in-depth discussion of mental spaces. 
Current developments in NTL make these questions all the more relevant. According to a 2010 posting by Lakoff on the 'cogling' mailing list, the issue is coming up 'as to how ECG and NL approaches should use simulation semantics to update mental spaces, keeping all of the correct results from the work of Gilles [Fauconnier] and others'. By what criteria should these spaces be identified, and what is the method for deciding which results are correct? So as to trace progress instead of merely moving on, it would be enlightening to see more discussion of how the different theories relate and what novel insights or beliefs motivate theorists to abandon - or leave out - ideas present in prior work or sister theories. To my knowledge, the topic of semantic domains has not been addressed in relation to metaphor since (Sweetser 1990), while the idea in CMT of experiential or semantic domain differences between source and target has not been addressed in CIT. There are plenty of unanswered questions, the answers to which might help scholars decide not just what they believe but why. Writing on recent developments in metaphor theory, Kövecses (2009: 22) says:

All the theories and approaches considered here contribute to an account of the meaning of metaphorical sentences such as 'This surgeon is a butcher'. No single theory explains everything about the process of meaning construction required for the sentence. In this sense, the different theories fit together and complement each other in a natural way.

The title of the paper is 'Recent developments in metaphor theory: Are the new views rival ones?' One would hope not! What struck me was the framing of theories as prospective rivals. Such combative framing leaves theorists with two unattractive options: defending indefensible ideas or being defeated; making the third alternative - avoiding confrontation - more appealing. Framing in terms of rivalry unwittingly entails an evasive attitude and an atmosphere of euphemistic complacency that are antithetical to the goal of scientific progress. Replacing the competitive framing with a cooperative one of dialogue seems more productive and intellectually satisfying. Engaging in argumentational dialogue means enabling each side to anticipate counterarguments and give each other opportunities to refining theoretical frameworks. In my estimation, facilitating a process of deliberation and judgment is a better alternative than prospects of victory or defeat and an unrealistic pressure, socioscientifically speaking, to get every part of a theory right the first time.

In their paper on conceptual blending and metaphor, Grady and colleagues (1999) characterize CMT and CIT as complementary approaches to metaphor, noting that the two theories differ with respect to their focus of attention: entrenched conceptual structure - global and static meaning - on the

\footnotetext{
${ }^{23}$ "...Surprisingly little attention is dedicated to discussing what mental spaces in fact are. Fauconnier and Turner (2002a) only dedicate 1 out of 400 pages to this issue. In fact, most of the time when mental spaces are introduced in some context, this is done by discussing what they are not (as in Fauconnier 1994) or by giving examples of mental space constructions, not by offering actual technical and/or philosophical definitions. Blending theory has made the issue of what mental spaces are very urgent. Many different things are put into mental spaces: conceptual structure, perceptual structure, linguistic form, single objects, structured scenarios, unstructured scenarios, very rich and complex scenarios, very simple scenarios, sound, physical form, color, emotion, etc. However, what do all these things have in common? The answer may of course be that they are all mental, but this then potentially entails that practically all mental processes are also mental spaces. This is a gross generalization, and what insight does it give if it places everything in the same category?' (Hougaard 2005: 57)
} 
one hand, online meaning construction - local and dynamic meaning - on the other. CMT is vulnerable to the critique that utterances are of interest only insofar as they serve as data for uncovering conceptual metaphors: an incomplete strategy of analysis as e.g. in literary studies. CIT has emphasized the pragmatic dimension of meaning; it includes, in its data, metaphors - among other examples of empirically observed or imagined speech - that do not originate in systematic conceptual pairings and whose motivation may be rhetorical as e.g. in humor (Coulson 2001). For Brandt and Brandt (2005), answering the question of what a metaphor means similarly lies in exposing, not underlying conceptual metaphors, but the conceptual process of meaning construction and interpretation.

One might get the impression that different theories are simply not asking the same questions; but the sum of theoretical differences between CMT and CIT can hardly be accounted for solely by reference to the general attentional shift from conceptual metaphor - source/target structures - to dynamic online construction of metaphor: i.e., instances of metaphor, whether derived from stable metaphorical concepts or not. Postponing judgment on whether - as Grady and colleagues (1999) and Kövecses (2011) suggest - the theories represent complementary approaches, I suggest looking at some of the things one notices when familiarizing oneself with them.

Like the neural theory of metaphor, CIT is a general theory of language and thought; metaphor is one of many phenomena subsumed under a descriptive model of conceptual integration. Whereas in CMT metaphors are defined by a T-is-S structure, no characteristic structure exists in CIT specifically for metaphors: they are not classified e.g. solely as simplex or double-scope blends. Metaphorical blends result from multiple 'inputs' merging into novel, temporary semantic units structured in accordance with a number of optimality principles (Fauconnier \& Turner 2002: 327-333). All blends are characterized by constrained mappings between spaces in a conceptual integration network, yielding emergent meaning in a blended space. No set of criteria exists for distinguishing utterances that prompt for metaphorical blends from other forms of expression.

Since no domain differences in CIT differentiate metaphors from other semantic structures, ${ }^{24} \mathrm{CIT}$ replaces CMT's directional view of projection from source to target with a non-directional view, where the projection goes from a number of inputs - minimally two - to the blend; and sometimes, in reverse, from the blend back to one or more of the inputs. As Rohrer (2007) observes, Fauconnier and Turner argue against the unidirectionality of metaphor mappings. In some cases, the process of blending may occasion re-examination of an input initially activated for purposes of rendering the target space more intelligible - i.e., a metaphorical 'source' - contrary to the belief expressed in e.g. Fernandez-Duque \& Johnson (1999: 85) that 'we understand aspects of the target domain via the source domain structures and not the reverse'.

\footnotetext{
${ }^{24}$ 'This surgeon is a butcher!' is considered metaphorical under most circumstances, but not 'this surgeon is a doctor!' What is the reason for that? How can one tell a metaphoric predicate from a non-metaphorical one?
} 
The widening of scope, enabling CIT to address bidirectional semantic effects in metaphor and beyond, seems advantageous. However, an inauspicious consequence to a multiple-input model with random numbering as the only designation of inputs is the absence of predicate structure: something is something else, metaphorically speaking.

To some degree, the relations between conceptual and linguistic metaphor and between domains and spaces remain unclear in cognitive studies of metaphor. ${ }^{26}$ Future research might help elucidate these and a number of other interesting issues, some of which I address in the following sections.

In what sense is language representational? The question has an evident philosophical dimension. The answer is of consequence to the methodologies chosen - be they e.g. computational, neuroscientific, or semantic introspection - to address hypotheses involving metaphor as well as mental spaces. The last fifteen years have witnessed a growing gap in the cognitive humanities - not least in linguistics - between representationalist theories and theories that try to avoid the term 'representation' (see e.g. Johnson \& Lakoff 2002). As Zlatev writes (2008: 144):

A unifying view of the basis of social cognition has been lacking.... When, for example, Gallese, Keysers and Rizzolati write "when only the cortical centers, decoupled from their peripheral effects, are active, the observed actions or emotions are "simulated" and thereby understood' (Gallese et al. 2004: 400), this is based on the assumption that neuron firing in itself possesses 'representational content' (Gallese 2005, Gallese \& Lakoff 2005) which is doubtful: it is the experimenters who attribute this 'content' on the basis of their observation of the temporal co-occurrence, i.e. a form of 'indexicality' (Sonesson 2007) between events in the world and neural patterns, not the animal, and not the (human) subject. The fact that mirror neurons fire during either observations/sounds on the one hand and executions of actions on the other, does not make them more representational than, say, neurons in the visual cortex responding [to] the particular aspects of the observed scene.

Metaphor theories like CIT are caught in a bind: if the theory identifies with the anti-representational position, where does that leave semantic analysis of the more-than-cool variety (think Lakoff \& Turner 1989), and how is the mental-space model of conceptual integration interpreted in a monist perspective? Much of the ambiguity concerning mental spaces might be due to an unresolved stance toward representations. This leads into a related topic: namely, the blending/binding question.

What is 'mental binding'? In CIT, binding is synonymous with blending: aka 'conceptual integration' or 'conceptual blending'. Turner \& Fauconnier (2003 [1998]: 133) propose a hybrid,

\footnotetext{
${ }^{25}$ Brandt (2013) offers an example of how bidirectional semantic effects can be handled in an analytic framework with asymmetric predicate structure. See especially the comments in Section 3.1.1.3 on the Menendez Brothers Virus joke presented in (Coulson 1996, 2001).

26

${ }^{26}$ As Tendahl and Gibbs (2008: 1841) note, it remains an open question how best to model online metaphor interpretation in cases where entrenched mappings exist between the topic and vehicle domains; 'it is not clear from cognitive linguistic studies or the extant psychological experiments whether people merely access the conceptual metaphor [e.g. LOVE RELATIONSHIPS ARE JOURNEYS] as part of their comprehension of an expression [e.g. "My marriage has hit the rocks"] or whether people must first access the conceptual metaphor and use that information to infer the intended meaning of this expression'. Of relevance to CIT is the question: If the schematic source domain translates into a source space, in blending analyses of linguistic metaphors derived from orientational metaphors (e.g., MORE IS UP), what would be the content of a generic space, given that the source space is already schematically abstract?
} 
'mental binding': 'conceptual integration - also known as "blending" or "mental binding" - is a basic mental operation whose uniform structural and dynamic properties apply over many areas of thought and action, including metaphor and metonymy'.

A common way to describe the particular neural processes involved in perceptual integration is via a binding schema: $c f$. the notion of perceptual binding. Integration at the perceptual level of consciousness involves contours, chromatic qualities, and other primitives that are 'bound' to each other in the process and sent off as integrated wholes, so that when one perceives an entity, one perceives all the properties at once. Fauconnier and Turner's suggestion that this final, integrated result be called a conceptual blend ${ }^{27}$ gives rise to a methodological question: if the neural binding involved in e.g. construction of a display of visible objects is inaccessible to consciousness - as is manifestly the case (no amount of concentration will allow one to experience one's own brain) - how can the cognitive semanticist identify it and diagram the process? One finds in cognitive linguistics descriptions of grammatical structures and linguistic meaning on the one hand and, on the other, physical and chemical events to which the analyst has no introspective access but must observe indirectly, by use of technological probes, and interpret as indicative of conceptual activity.

From a representationalist standpoint, linguistic meaning lends itself to two kinds of description: what goes on in the brain, and what goes on in the mind. Imaginative enactment, or 'mental simulation', is performed both neurally and experientially, calling for two distinct descriptions. By contrast, the anti-representationalist view defended in the neural theory of language posits that imaginative enactment is only performed neurally: what goes on in the mind just is what goes on in the brain.

\section{RELEVANCE AND THE EMERGENCE PROBLEM}

The critique in this section concerns the issue of relevance - not only as it relates to the class-inclusion view of metaphor and to relevance-theoretic notions of it, but other accounts as well, including CMT and CIT. As I aim to demonstrate, the problem identified is of general concern for all theories that neglect communicative intention as a factor in meaning construction.

The concept of relevance has sparked off a whole theory under its name (Sperber \& Wilson 1986); it is the motivation for one of the optimality constraints in CIT: The Relevance Principle (Fauconnier

\footnotetext{
27 'The perception of a single entity, like a cup, is an imaginative neurobiological feat still very poorly understood by neurobiologists. That perception, which is available to consciousness, is the effect of complicated interaction between the brain and its environment. But we integrate that effect with its causes to create emergent meaning: the existence of a cause, namely, the cup, that directly presents its effect: its unity, its color, its shape, its weight, and so on. As a consequence, the effect is now in its cause: the color, the shape, and so on are now intrinsically, primitively, and objectively in "the cup." In perception, at the level of consciousness, it is usually only the blend of cause and effect that we can apprehend. We cannot fail to perform this blend and we cannot in consciousness see beyond it. Consequently, this blend seems to us to be the most bedrock reality....' (Fauconnier \& Turner 1999: 3; see also Fauconnier \& Turner 2002: 56, 78, 82, 90, $105,108,118,210,267,292,389)$.
} 
1997: 65-66, 137-138). The historical division of semantics and pragmatics into separate disciplines is challenged by the cognitive-linguistic perspective, in opposition to the generative tradition in linguistics and the orientation in philosophy of language toward propositional sentences. Heralded by the novel, usage-oriented view of language appearing in the '60s (Austin 1962, Benveniste 1966, Searle 1969) - which demonstrated the role of sentences as utterances - theories like mental space theory and CIT represent a conceptual shift away from preceding paradigms, disputing the old idea that sentences are bearers of meaning independently of their function in human cognition:

Sentences bring together, in one linguistically homogenous form, heterogeneous and incomplete information as to the cognitive constructions to be performed within a context for the purpose of constructing meaning. Meaning ensues when such operations are performed, but is not itself directly assignable to sentences (Fauconnier 1994: xx).

The idea of 'constructing' meaning is a modern - or rather postmodern - one, materializing out of the new focus on the human subject as an indispensable factor shaping language and thought. Language is a conceptual means and not a symbolic manifestation of mind-independent states of affairs. In the first book introducing philosophers and linguists to the concept of blending, Fauconnier calls attention to the need for theoretical adjustment, proclaiming (1997: 5) that:

[A] shortcoming of modern work, found in this case both in linguistics and in philosophy, is the sharp emphasis on separating components (e.g., syntactic, semantic, pragmatic) and attempting to study the grammatical or meaning structure of expressions independently of their use in reasoning and communication.

Sentences are no longer to be seen as propositions defined by truth conditions or as surfacestructure/deep-structure pairings independent of pragmatic circumstances but as expressions: that is, as components of discourse. Fauconnier writes (1997: 163-164, emphasis added):

The participants in the conversation are prompted grammatically to construct a blend, to find contextually relevant features that produce inferences, and to export such inferences via the connectors. The rich meaning that will ensue is not inherently contained in the grammatical structures. What the grammar does is specify a range of constructions of blends from which to choose and on which to elaborate. This is why language functions so differently from codes, logical truth-conditional systems, and the like. It never does more than set a very schematic stage for the meaning that is going on to be built and negotiated locally in usage.

In this philosophical perspective, sentences require a disambiguating pragmatic context: "when a sentence is examined in isolation, and its interpretations are studied, it is necessary to construct implicitly a discourse in which to interpret it' (Fauconnier 1997: 55).

Of course, this should be true of metaphorical expressions as well; and yet a theoretical ambivalence prevails in metaphor theory - including CIT - regarding the situatedness of language. In mental-space terms, the discourse base space contains the referents of the sentence rather than 'the 
situation of address' (Benveniste 1971: 218) ${ }^{28}$ : the speech event, its participants, and its immediate circumstances.

When mental spaces are 'blended', according to CIT, structure from certain inputs is favoured over other structural elements, and the input spaces themselves contain partial representations: locally constructed wholes, not entire experiential domains. However, no technical explanation is offered why the favoured structure is favoured or why those partial representations were selected.

The structural configuration of metaphorical integrations is flexible because it depends on context. Turner writes (1991: 107; emphasis added): 'in general, there is no fixed structure of the target input space that the source input space must match, because the target input space has different structure under different recruitments to it'. Turner and Fauconnier seem in perfect agreement that the differing recruitments ( $c f$. CIT's notion of partial projection) are motivated by what is deemed relevant in context; yet these pragmatic motivations are absent in the blending model of meaning construction.

Seeking to incorporate aspects of relevance into the diagrammatic blending model, Brandt and Brandt (2005) present a revision of the network's architecture that includes the grounding of meaning in communicative acts - borrowing ideas from relevance theory, speech act theory, cognitive grammar, and semiotics. Inputs are defined as the expression and content aspects of a sign, and the blend as a Virtual space - setting blended spaces (e.g., metaphorical blends) apart from situations without virtual identification ${ }^{29}$ as when breakfast and lunch combine in the word 'brunch'. On this account, space building is grounded in the discourse base space ${ }^{30}$ where the expressive acts occur. This, in turn, makes it possible to distinguish different aspects of semantic-pragmatic relevance. Indeed, the model delineates three aspects: situational, argumentational, and illocutional relevance.

The category 'shared structure between the inputs' is conceived as context sensitive - as categories generally are in CL. The structure that inputs have in common is specified by what is situationally relevant - in contrast to the idea in CIT that shared structure exists as a list of entities and relations - independent of any motivation in the conceptualizer to evoke them as similarities within a 'generic' space. The blended space contains elaborate figural images; the generic space - one of the stock spaces in a standard mental space blend - contains abstract, skeletal structure (Turner \& Fauconnier 1995; Fauconnier \& Turner 1996, 2002). The generic space - summarized by Gibbs (2000:

\footnotetext{
${ }_{28}^{28}$ Langacker's 'ground': (2002: 7-8, 1999: 79).

${ }^{29}$ The blend is momentarily treated as if it were real and yields real inferences even though it is not vested with belief.

${ }^{30}$ See also (Coulson \& Oakley 2005) for their employment of a 'grounding box' in their mental-space analysis of figurative meanings. The phenomenon is characterized as a box because, in the authors' analysis, it is not thought of as a mental space but as a list: i.e., the box 'contains the analyst's list of important contextual assumptions...' (Coulson \& Oakley 2005: 1517). Brandt $(2010,2013)$ examines the base space, defined as the space of enunciation (see especially Chapter One and the sections 'Spaces and domains' and 'The semiotic base space' in Chapter Three).
} 
349) as 'some additive space of what two or more domains have in common' - traces back to Lakoff and Turner's (1989) concept GENERIC IS SPECIFIC ${ }^{31}$, developed further in (Turner 1991, 1996).

Turner's (1996: 87) argument for the conceptual existence of a generic space is that one can reach a generic interpretation without projecting it onto a specific target. He offers as a key example proverbs, which he describes in terms of generic-level information projected to a generic space whose abstract story may then be applied to unlimited target spaces. Possible contents of the generic space in essence, the fundamental properties instrumental to the structuring of human experience - are (Turner 1991: 161):

...Basic ontological categories (such as entity, state, event, action, and situation), aspects of beings (such as attributes and behavior), event-shape (such as instantaneous or extended; single or repeated; completed or open-ended; preserving, creating, or destroying entities; cyclic or without fixed stages that end where they begin), causal relations (such as enabling, resulting in, bringing about, creating, and destroying), image-schemas (such as bounded regions, paths, forces, and links), and modalities (such as ability, necessity, possibility, and obligation).

Generic structures are constituted by mappings that establish counterpart connections between input spaces to guide the blending. The concept of mappings appears already in (Lakoff \& Johnson 1980) and is a central component in mental space theory. A mapping is 'a correspondence between two sets [read: mental spaces] that assigns to each element in the first a counterpart in the second' (Fauconnier 1997: 1, Footnote 1).

Similarities in e.g. image-schematic structure make mapping possible, aligning comparable entities and relations in the inputs. The concept of counterparts presupposes structural comparability, on the basis of which elements in the source and target inputs may be fused or contrasted in a blend. Remaining unmatched structure in either space needs only be compatible, so as not to cause unmotivated conflict. Some version of CMT's Invariance Principle - asserting that mappings preserve the image-schematic structure of the source domain consistent with the inherent structure of the target domain - may still apply, adjusted to mental spaces instead of domains of experience, in the form of constraints on the projection of structure to the blend from the inputs. "[The invariance principle] does not require that the image schema projected from the source already exist in the target before the

\footnotetext{
${ }^{31}$ Supposedly this is a conceptual metaphor even though neither source nor target constitute domains.

32 Interpreting the principle so that is it consistent with available data requires specification of what is entailed. As Coulson writes (2001: 171-172) - based on insights arrived at, in part, from analysis of the digging-yourown-grave metaphor - 'these examples ["he's digging his own grave", "it's not too late to exhume ourselves from the shallow grave we've dug for ourselves" (statement about the plight of the American educational system)] show that the inferences suggested by metaphoric utterances need not result from projections based on shared relational structure. In this respect, the source domain in a metaphor is less important than previously thought [cf. the Invariance Principle], as causal structure in the source can be quite irrelevant for the resultant construal of the target domain'. Coulson and Oakley (2003) argue that, in some instances, the topology principle - one of the optimality principles in CIT (a parallel to the invariance hypothesis in exerting pressure to preserve relational structure: p. 59) - can compete with other optimality constraints, such that maximal preservation of relational structure may be 'traded off' in favour of other relevant concerns (p. 61).
} 
projection, but instead that the result of the projection not include a contradiction of image schemas' (Turner 1991: 30).

It is worth noting a conflict in CMT not inherited by CIT, in part because CIT does not aim at explaining the origin of abstract domains. In CIT as in CMT, one does not necessarily have counterparts for every entity or relation in another space; it also cannot be the case that the target space has no structure at all. Since (Lakoff \& Johnson 1980), there has been an unspoken conflict in CMT between recognition of structural attunement as a factor in explaining constraints on the compatibility of source/target constellations, and a desire to portray abstract domains as largely or entirely structured by more concrete domains via metaphorical projection such that the physical domain of sensorimotor action and perception can be claimed ultimately to ground the various other domains. In CMT, projections are thought to occur between domains that are structurally compatible: a notion supported, in part, by the Invariance Principle); but, contrary to this, CMT also claims that, in some cases, the target domain can be inherently unstructured: i.e., the target subject matter need have no structure of its own. The longevity of the idea of unstructured target domains is evident, given its appearance as late as (Tendahl 2009:156), which refers to target domains with 'no (or only little skeletal) structure'.

Whether instantiating entrenched mappings between domains or not, in CIT the blends of mental spaces rely on structural compatibility as a factor motivating e.g. metaphorical mappings. Structural compatibility explains why some mappings are felt to 'fit' while others would never be considered. This is true of domains as well as spaces. The question is whether similarities abstracted from input spaces are represented as contained within a generic space.

Though it may be analytically possible to construct an exhaustive list for every blend, it seems implausible that such a list space is evoked in the mind of the conceptualizer in the act of constructing meaning. The presence of an extra space does not help explain the process of constructing the meaning of a blend - which is probably why it is generally absent from verbal descriptions of how particular meanings are derived - in some cases, even from the diagrams themselves.

Sweetser writes (2006: 33; emphasis removed) : '...mappings between input spaces are normally structured by a generic space .... However, it is unclear, either in Sweetser or elsewhere in the literature, what constitutes normal conditions: when are mappings presumed to be structured by a generic space and when not?

One might reasonably expect some sort of phenomenological motivation for positing the existence of this kind of representation. Without it, the space gains the appearance of an unnecessary appendage, of no obvious relevance to understanding the semantics in question. This is particularly

\footnotetext{
${ }^{33}$ The questionable reality of domains without internal structure aside, one argument against viewing certain metaphors as transferring structure to a target with little or no structure is that, in primary metaphors, it is the source domain that has 'skeletal' structure. Moreover, one would expect boundless variation in the metaphorical coupling of domains, if - as is claimed - one domain can be inherently unstructured. This is not what one sees: there are constraints on which domains can map onto which other domains. To take an example from Lakoff (1993: 219), death 'is not metaphorized in terms of teaching, or filling the bathtub, or sitting on the sofa'.
} 
notable, I think, in the case of so-called 'simplex blends', composed of especially meager spaces and claimed to account for construction of the meaning of sentences like 'Paul is the father of Sally' (Fauconnier \& Turner 2002). ${ }^{34}$ Generic space often contains roles in blending analyses; but, in the case of simplex blends, role and filler are contained in Input One and Input Two respectively. ${ }^{35}$ In the analysis of Paul (filler) as a father (role), one ends up with the category man (the gender) in the generic space - which does not add to understanding the semantics in question and, in any case, seems somewhat contrived. ${ }^{36}$ In another simplex-blend example - 'this is the top of the building' - 'this' and 'the top' exist in a focus input. They are said to map onto 'a whole vertically oriented thing' and 'a vertical extremity' in a whole-with-parts frame input. This may sound rather odd: that the building needs a whole-with-parts mapping to be conceived as a whole with parts; but what is striking is the absence of any mention of generic space. It is hard to see what the contents would be, other than a 'whole' or 'vertical thing': i.e., other than a reiteration of the 'vertically oriented thing' input.

To get to the heart of the matter concerning relevance, one must attend to what Vega Moreno (2007) has dubbed 'the emergence problem'. The crux of the disagreement between various theories of metaphor is best illustrated by the controversy over the infamous butcher-surgeon metaphor. It presents certain challenges to metaphor theories - not least to CMT - since it is not conceptually motivated by experiential convergence or permanent cross-mapping. The metaphorical expression 'this surgeon is a butcher' activates the experiential domains of butchery and surgery: two domains not systematically associated in advance. The utterance linking the 'butchery' source domain to the 'surgery' target domain is not a linguistic instantiation of an entrenched conceptual metaphor: e.g., *MEDICAL PRACTICE IS FOOD PROCESSING or *SURGEONS ARE BUTCHERS. Neither does it bank on a concrete-to-abstract directionality of conceptualization: source and target could

\footnotetext{
${ }^{34}$ The $X Y Z$ form - ' $X$ is the $Y$ of $Z^{\prime}$ - was originally of semantic interest because of the hidden $W$ in $X Y Z$ metaphors - ' $X$ is to $Z$ as $Y$ is to $W$ '. Mental spaces were shown to help account for the figurative meanings thus analyzed (see e.g. Turner 1996). However, by (Fauconnier \& Turner 2002; especially Chapter Eight), interest has shifted from the underlying semantics of $X Y Z$ metaphors ('vanity is the quicksand of reason' [Sand], 'the Child is father of the Man' [Wordsworth]) to their syntactic form; so the authors include in their discussion such literal statements as 'Paul is the father of Sally' or 'this is the top of the building'. $X Y Z$ blends have come to be defined, not semantically, but in terms of the syntactic form of linguistic units; the construction itself prompts a blend. '...The syntax and mapping scheme of "The Child is father of the Man" are the same as the syntax and the mapping scheme of "Paul is the father of Sally"' (Fauconnier \& Turner 2002: 142). 35

Attributes and the entities to which the attributes apply are thus thought to be represented separately.

${ }^{36}$ In addition to 'local' generic spaces with structure abstracted from inputs, Fauconnier and Turner claim the existence in multiple-integration networks of an unspecified number of 'global' generic spaces as abstractions of one of more spaces in the network. 'A blended space is a mental space, and we can always make a more abstract version of a mental space'. Using 'this surgeon is a butcher' as example, the authors suggest a host of abstractions fitting the blend. 'One very abstract generic space fitting this blend has only a person who acts. A less abstract one has an actor and something acted upon. A still less abstract space has an actor and the physical object (living or not) acted upon. A generic space derived in this manner might coincide with the local generic space over the inputs, or be more abstract, or be more specific. Or it might contain abstract structure corresponding to emergent structure in the blend, in which case it will not fit the inputs' (Fauconnier \& Turner 297-298). The authors do not state under what circumstances, how, or for what reason these spaces exist; perhaps the phrase 'derived in this manner' indicates that stating their conceivability is a method of derivation.
} 
conceivably be reversed, given the right context. ${ }^{37}$ On every account, the metaphor is taken to be a criticism of the surgeon; in most analyses (e.g. Grady et al. 1999, Fauconnier \& Turner 2002), it is said to predicate incompetence. Glucksberg (1998: 42) writes of the surgeon-as-butcher that he is 'a member of the category of people who botch jobs in reprehensible and often appalling ways'; Brandt and Brandt (2005) write that he is reproached for practicing his profession with an attitude of reckless indifference; he is hence said to act in an ethically indefensible manner. Vega Moreno (2007) mentions incompetence, malice, negligence, and carelessness as possible implicatures. No account of the meaning of the butcher-surgeon metaphor fails to interpret it as a criticism, illustrating that the metaphorical relation between source and target cannot be one of mere projection. ${ }^{38}$ In CMT, meaning derives from the source domain; but nothing inherent in the experiential domain of butchers warrants negative evaluation. How does the critical meaning emerge?

Glucksberg (1998) attempts, unconvincingly, to define 'butcher' as having an inherently negative encyclopedic meaning; the alleged meaning regrettably presupposes the existence of butcher metaphors. Vega Moreno (2007) uses this to criticize Glucksberg's attribution model of metaphor.

Charting historical theory development leading up to the present, Vega Moreno describes how much contemporary research on metaphor has moved away from 'feature matching' models of metaphor - the idea that metaphor comprehension involves matching properties between topic and vehicle - toward 'attribution' models, by which metaphor interpretation is a matter of attributing a subset of properties of the metaphor vehicle to the metaphor topic. 'A very serious problem for both

\footnotetext{
${ }^{37}$ Sperber and Wilson (2008) mention the possibility of reversal. They offer the example 'this butcher is a surgeon'. Note, however, that Sperber and Wilson do not analyze the sentence as an utterance. They hypothesize an apparently context-free, static meaning as a symmetrically reversed version of their - similarly isolated and context-free - example 'this surgeon is a butcher'. 'The interpretation of ['this butcher is a surgeon'] is equivalent of the one for ['this surgeon is a butcher'], and involves the construction of an ad hoc concept SURGEON*, denoting people who cut flesh with extreme care. A butcher who is also a SURGEON* is outstandingly competent and trustworthy. The predicates BUTCHER* and SURGEON*, along with the implication of incompetence for a surgeon who is a BUTCHER* and of competence for a butcher who is a SURGEON*, emerge unproblematically in the course of an inferential comprehension process guided by the search for relevance' (Sperber \& Wilson 2008: 97-98). I am skeptical of this analysis, first and foremost because the authors overlook the significance of contextual grounding and seemingly take for granted that the metaphor has a fixed meaning - despite the denunciation, in relevance theory, of fixed metaphorical meanings. If the butcher is a surgeon, the butcher is said to be competent. Equally likely is the possibility that the metaphorical surgeon predicate serves as a complaint that the butcher in question is not efficient enough. Separating meat from bones 'ain't surgery': it needs to be done with accuracy and speed. A butcher 'being' a surgeon - doing his job as a surgeon would - would not, in this scenario, be doing his job competently.

${ }^{38}$ Grady and colleagues (1999) make just this point: simple projection cannot account for emergent meaning. It is unclear how CMT should analyze the butcher-surgeon metaphor. Would its proponents propose that the emergent meaning is predictable from the source category? Lakoff (2008: 32) attempts a solution involving the formula A PERSON WHO PERFORMS ACTIONS WITH CERTAIN CHARACTERISTICS IS A MEMBER OF A PROFESSION KNOWN FOR THOSE CHARACTERISTICS. Lakoff characterizes this as a formula for conceptual metaphor, but it reads more like a formula for hyperbole: e.g., one may jokingly refer to someone funny as a 'comedian'. In any event, it is hard to see how A PERSON WHO PERFORMS ACTIONS WITH CERTAIN CHARACTERISTICS could conceivably become a useful domain in human experience. Tendahl and Gibbs (2008: 1830) express a similar skepticism, calling for further linguistic analyses 'to clarify the exact conceptual metaphor at work'.
} 
matching models and attribution models is that sometimes the set of properties which are attributed to the topic are not stored as part of our representation of the vehicle...' (Vega Moreno 2007: 75). To illustrate, Vega Moreno offers two metaphorical examples, the first being a butcher-surgeon metaphor:

(1) Doctor: I am afraid the surgeon who performed a caesarean on your wife perforated both ovaries. I had no choice but to remove them. Husband: I want that surgeon out of the hospital. That surgeon is a butcher!

(2) Jane: I know I have to speak to my boss but I am afraid of him. He is such a bulldozer!

The speaker in [1] may be expressing the thought(s) that his wife's surgeon is highly incompetent, dangerous, careless, etc. The speaker in [2] may be expressing the thought(s) that her boss is stubborn, difficult to deal with, that he is not respectful to her, that he undermines her needs, her thoughts, etc. The problem raised by these examples is that our knowledge of butchers does not include the assumption that butchers are negligent and careless and our knowledge of bulldozers does not include the assumption that they are disrespectful or stubborn. Since the set of intended properties are not stored as part of our representation of the vehicle, they can be neither matched with the properties of the topic nor attributed to it. Both matching and attribution models therefore fail to explain how these properties are derived (Vega Moreno 2007: 76)

On a semiotic account, the construal of the butcher space is determined by relevant aspects of the target: the patient's caesarean supposedly motivates the elaboration - 'composition' and 'completion' in CIT terms - of the butcher and surgeon spaces and hence the negative evaluation of the surgeon. Other explanations seek to derive the meaning from the concepts evoked by the sentence independently of any speech event. Glucksberg and Keysar (1990) argue that metaphors are understood as class-inclusion statements. They describe metaphorical predication as a matter of including the target in a superordinate category of which the source is a prototypical example ${ }^{40}$; alternatively, the source entity has a metaphorical meaning fixed in the lexicon, which is then ascribed to the target. 'The categorical statement... My surgeon was a butcher assigns my surgeon to the class of people who are incompetent and who grossly botch their job' (Glucksberg \& Keysar 1990: 9). On this view, it would appear possible to predict the meaning of the form ' $\mathrm{T}$ is a butcher': $\mathrm{T}$ is someone 'grossly incompetent in tasks that require finesse, skill and expertise' because that is a meaning of 'butcher', according to the dictionary entry. The reference to a superordinate category or 'class' seemingly circumvents the need for conceptual integration in a third mental space; in this respect, the

\footnotetext{
39 "Glucksberg and colleagues often illustrate their ideas with the example "my surgeon is a butcher". They argue that in understanding this metaphor, the hearer aligns vehicle properties and topic dimensions, thus constructing an attributive category "people who are incompetent and who grossly botch their jobs", which the vehicle typifies and which can assign a negative value to the dimension of "skill" provided by the topic...' (Vega Moreno 2007: 78).

40

Vega Moreno (2007: 74) points out difficulties with this. First, the source category - e.g., 'butchers' - can potentially be members, even typical members, of an indefinite number of ad hoc categories. 'Second, according to Barsalou's experiments, prototypicality is an unstable notion which varies across contexts, points of view, individuals, etc. with the typicality of a given member arising as a byproduct of constructing an ad hoc category rather than as a prerequisite to the construction of that category. Third, even if we take prototypicality to be a stable notion, and assume that [the] metaphor vehicle can exemplify only a limited number of ad hoc categories..., none of these categories may be the one intended by the speaker on a certain occasion ...'.
} 
theory is akin to CMT. The predicate is transferred from source to target, thereby including the target in the attributive category.

However, even if some variability is allowed - seeing the metaphorical predication as the result of category interaction between source and target, taking into account the possibility of variant targets - explanatory difficulties arise. If one assumes, per Glucksberg (2001), that attribution of properties is a function of possible superordinate categories exemplified by the source category and conceptual dimensions offered by the target, one concludes that the category of incompetent workers - of which 'butcher' is claimed to be an exemplar - fits the dimension 'skill' in the target. The dimension 'skill' is thought to be inherently salient to the category 'surgeon', suggesting a view of categories as static and context independent. In a sense, Glucksberg acknowledges 'relevance constraints imposed by the topic' (Glucksberg 2001: 55); but, because he thinks of relevance strictly in relation to source and target as static categories, relevant constraints are similarly static and context independent. His model does not explain how a dimension is selected - a shortcoming partly due, I think, to topical concepts being imagined as categories rather than scenarios or 'partial and temporary representational structure[s] which speakers construct when thinking or talking' (Grady, Oakley \& Coulson 1999: 102).

I note three other problems with the analysis. First, 'my surgeon was a butcher' can only be described as a categorical statement insofar as one ignores what the metaphor is about. There is no reason why the ad hoc superordinate category 'the set of workmen who are incompetent and grossly botch their jobs' should be constructed, if the intended inference is about a particular surgeon, as it is in the example given. The intention is hardly to categorize the surgeon as belonging to a set, so the critical question is a methodological one: why, in analyzing the metaphor, construct a category that is not warranted by any relevant circumstances pertaining to the situation where the metaphor is produced?

Second, the class-inclusion account of metaphor skirts the issue how '.. is a butcher' becomes a negative predicate of the target entity $T$. The predicative meaning 'my surgeon was incompetent and grossly botched the job' is said to be the result of a logical operation, given the predetermined lexical meaning of 'butcher'. The predicate ascribed to the surgeon comes from one of the Webster dictionary entries for 'butcher': 'an unskillful or careless workman' (Glucksberg \& Keysar 1990: 9). Since butchers are not generally thought of as grossly incompetent or 'unskillful or careless' - they are not prototypical instances of 'the set of workmen who are incompetent and grossly botch their jobs' - how did the lexical entry 'butcher' acquire this conventional meaning? The answer, of course, is: from metaphor. Vega Moreno (2007: 78) notes the circularity of argument from a relevance-theoretic point of view:

There is an important problem inherent in this well-known example...: how can people construct the ad hoc attributive category 'people who are incompetent and who grossly botch their jobs' by selecting a subset of properties from the metaphor vehicle if the property of 'botching their jobs' is not part of our representation of butchers? Our knowledge of real butchers may include the 
assumptions that they cut and sell meat, that they use sharp knives, etc. It does not, however, include the assumptions that butchers are incompetent, negligent, careless or people who botch their jobs. If we thought butchers were generally incompetent, we would not trust them and would never buy food from them. Since these properties are not associated with the metaphor vehicle, and since the Class-Inclusion view takes the ad hoc attributive category to be formed by selecting properties from the vehicle, it is not clear how this category is ever formed. Lacking adequate machinery to construct the ad hoc category the speaker intended to convey in producing the metaphor, the Class-Inclusion theory cannot account for how emergent properties are derived.

Third, what is salient about the target may vary from instance to instance; it cannot be identified by any one dimension like 'skill'. Though it may be a valid generalization that 'butcher', used metaphorically, conveys a negative meaning, the attributes predicated vary and, in some instances, imply a more active agency, involving e.g. brutality or lack of compassion, than that implied in the examples discussed here.

Vega Moreno argues (2007: Ch. 3) ${ }^{43}$ that the problem causing these theoretical difficulties for various interaction theories, including CIT, is generally attributable to two things: (1) omission of any account of how the interaction between categories / domains / mental spaces is supposed to make meanings emerge and (2) exclusion of the speaker's intentionality as a factor in interpretation. She writes (2007: 75; emphasis added):

...Saying that metaphor interpretation (and category construction) depends on an interaction of topic dimensions and vehicle properties cannot explain how an utterance can have an indefinite number of possible interpretations, or how the hearer chooses or constructs a hypothesis about the one intended by the speaker. Not only can a single dimension-property combination open the way to a range of possible interpretations [as in $3 \mathrm{a}$ and $3 \mathrm{~b}$ below], in many cases a good number of properties of the vehicle can be used to characterise a good number of topic dimensions. Since

\footnotetext{
41

Notice, however, that instances of metaphor exist where the source domain of butchery contributes to a framing that is not laden with negative meaning: e.g., the Danish metaphor at skære ind til benet ('to cut to the chase', lit. 'to carve close to the bone') means to make a straightforward and precise ("clear-cut") assessment eliminating inessential material. The metaphor exploits the imagery of cutting meat off a bone with high precision so as to eliminate waste - an economically sound practice associated with skillful butchery. Thus applied to the domain of argumentation the domain of butchery serves to enhance the idea of skillful exactitude.

42

Henry Kissinger in conversation with President Nixon (The Nixon Tapes, 25 April 1972). NIXON: The only place where you and I disagree... is with regard to the bombing. You're so goddamned concerned about civilians and I don't give a damn. I don't care. KISSINGER: I'm concerned about the civilians because I don't want the world to be mobilized against you as a butcher. (Transcript available at the the National Archives.) For further examples, see (Brandt \& Brandt 2005; Brandt 2013: Ch. 3).

43 'A metaphor, for example a nominal metaphor of the form $X$ is $Y$, may be used to convey a wide range of different meanings ["That lawyer is a shark", "John is an iron bar"], and involve the formation of a wide range of different ad hoc categories.... The question is: what determines the formation of the different ad hoc categories...? The Class-Inclusion Theory provides no answer to this question. According to this theory, aligning a metaphor topic and a metaphor vehicle should result in the emergence of a combination of topic dimensions and vehicle properties which should form the basis for the construction of the ad hoc category to which topic and vehicle belong, and so the basis for the interpretation of the utterance. If this is all there is to metaphor interpretation, aligning the same topic and vehicle should result in the emergence of the same combination of dimension and property, the construction of the same attributive category and in the derivation of the same interpretation across contexts. This is clearly not the case' (Vega Moreno 2007: 73-74). Vega Moreno does not direct her criticism solely at CIT but interactive views in general.
} 
every combination offers a potential ad hoc category to which both topic and vehicle can be said to belong, how does a hearer know which one was intended? The Class-Inclusion Theory lacks adequate interpretive tools to answer this question.

Vega Moreno gives two examples of the same dimension-property combination yielding different implicatures (3a, 3b), and two illustrating variations on vehicle (i.e., source) properties (3c, 3d):

(3a) (Of a surgeon who has been negligent) That surgeon is a butcher.

(3b) (Of a pianist who has played terribly badly) The pianist butchered the sonatas.

(3c) (Of a teacher who fails most of the class) That teacher is a butcher.

(3d) (On a gruesome crime scene) This man is a butcher!

She writes (2007: 73):

I agree with the 'interactive' idea that the presence of the metaphor topic has an effect on the set of attributes or assumptions which we access from the metaphor vehicle on a given occasion (e.g. the activation of a certain concept in memory may have an effect on how we process incoming information). However, I don't agree with the assumption that by putting a certain topic and a certain vehicle in the same sentence, the right combination of dimension and attribution will emerge, by magic, providing an adequate basis for interpretation.

This leads into a discussion of the problem of emergence (2007: 76-78):

Properties which are not part of the hearer's representation for the metaphor vehicle or the metaphor topic, but which seem to emerge in interpreting a metaphor, are often referred to in the literature as 'emergent properties' or 'emergent features'. Examples [1] and [2] show how emergent features play a crucial role in arriving at the meaning the speaker intended to communicate in uttering a metaphor. It follows from this that any adequate account of metaphor interpretation should aim to provide an explanation of how these emergent features are derived. I shall refer to this as the 'emergence problem' of metaphor interpretation.... Saying that features emerge from interaction is not explanatory: it is necessary to spell out how it is that they are derived. One should then expect the cognitive models inspired by Black's ideas [metaphor interpretation as essentially an interactive process between two concepts or domains] to provide a detailed account of the pragmatic or cognitive steps involved in the derivation of new mental structures and the emergence of new properties. Unfortunately, although a substantial amount of experimental research has been stimulated by the romantic idea of metaphor as powerful and creative, very little work has been done to explain how emergent properties are derived. In fact, experimental work which deals explicitly with the issue... has mostly been concerned with presenting evidence for the existence of emergent features rather than explanation of the cognitive processes involved in their derivation. The lack of work on accounting for the derivation of emergent properties in metaphor interpretation is surprising not only because solving the 'emergence problem' is essential for understanding how metaphors are understood but also because most modern approaches to metaphor are based on the assumption that something new is created in interpreting a metaphor. The issue of emergent properties is a thus a problem for all theories which aim to account for how hearers arrive at the interpretation intended by the speaker's use of a metaphor....

Despite the advantages of modern cognitive approaches to metaphor, 'a problem common to all these approaches is that they lack the pragmatic inferential mechanisms necessary to guide the comprehension process and to account for the attribution of properties and the derivation of emergent properties taking place in interpreting a metaphor' (Vega Moreno 2007: 85, emphasis added) - so, too, in the case of blending theory, its own advantages notwithstanding. In her efforts to pinpoint the main 
challenge facing the theory, Vega Moreno critiques Grady and colleagues' (1999) analysis of the butcher-surgeon metaphor, explaining why the processes of composition, completion, and elaboration cannot - as Grady proposes - account for metaphor comprehension. She poses the same question motivating the inquiry in (Brandt \& Brandt 2005): what determines the emergence of meaning? 'Scholars pursuing Blending Theory argue that emergent properties arise naturally from the construction of the blended space. But if a blended space is constructed by projecting information from different sources, namely input spaces and encyclopaedic information, how can anything “emerge"?' (Vega Moreno 2007: 80)

Vega Moreno (2007: 80) summarizes how blending analysis take one through the vital steps of constructing a metaphorical representation of a butcher-surgeon but misses a step that would allow one to get from the metaphorical blend to the critical meaning intended by the metaphor's utterer:

It is important to notice, however, that the blended space provides us with a certain representation which cannot be the one the speaker intended the hearer to derive. The speaker of the metaphor above, for instance, does not intend to communicate that there is a butcher operating on a patient but that there is a certain surgeon who does not do his job properly. The blended space provides information which is indeed consistent with a literal interpretation of the utterance, the interpretation that my surgeon is a real butcher! Attempting to explain how one gets from this interpretation to the intended one implies a variant of the standard serial model of metaphor interpretation [based on the assumption that derivation of metaphorical meaning relies on rejection of literal meaning] so widely criticised among psychologists. Maybe the hearer is simply supposed to take the blended space metaphorically so as to derive the set of thoughts the speaker intended to convey. If this is true then forming the blended space does not account for how metaphors are understood and just takes us into needless circularity.

Vega Moreno's critique of blending theory ultimately serves as an appeal to take seriously into account the speaker's communicative intentions (2007:81):

One important problem with Blending Theory, and with many psycholinguistic approaches to metaphor, is that it does not take seriously into account the speaker's communicative intentions. I have shown earlier how a single metaphor 'John is an iron bar' or 'my lawyer is a shark' can be used to convey a number of different meanings on different occasions. In order to explain this in terms of Blending Theory, one would have to say the hearer forms a different blend [on] every occasion. It is not clear how this can be done. Since the projection from input spaces to the blended space is taken to be based on structural similarities between spaces and not in the search for the recognition of speaker's intentions, there is no apparent reason why different elements from an input space would be projected into the blended space on different occasions. In fact, even if the explanation of different interpretations were to be given in terms of different types of completions of the blend, the theory cannot explain what determines these different completions.

Given Vega Moreno's arguments, it is not surprising that her solution emphasizes discourse comprehension and derivation of the inferential meaning determined by the speaker's intentions.

\footnotetext{
${ }^{44}$ The CIT diagram features a surgeon space, a butcher space, and a blend of the two spaces in which the fused agent has a surgeon's goal but uses a butcher's means to achieve it. In a generic space, an abstract agent uses general means to achieve a general goal. The intended meaning of incompetence derives from a crossover between the goals and means of butchers and surgeons, respectively, creating a mismatch of using a butcher's means for the surgeon's goal of healing a patient. The analysis omits any explanation for why the agents' crossover does not have a surgeon's means and a butcher's goal, which might equally have been the case.
} 
Perhaps more surprisingly, her proposal continues in the tradition of CIT or attribution theory in adopting Glucksberg's insertion of $a d$ hoc categories into the interpretive analysis. ${ }^{45}$ She adds an extra analytic dimension meant to close the attested gaps in CIT, in the form of an inferential process yielding the intended implications: '.. an inferential process which may involve several inferential steps, and several instances of pragmatic fine-tuning, before the resulting implications may be plausibly taken to apply to [the target]' (Vega Moreno 2007: 110; see also Sperber \& Wilson 2008).

The examples she analyzes are all nominal metaphors explicitly linking a target and a source: $T$ IS $S$; presented with no - or minimal - discourse context. As a result, the meaning to be explained remains vague, typically represented as a short list of attributes followed by 'etc.'. In the butchersurgeon example ('that surgeon is a butcher'), her analysis of the inferential process consists of a sixteen-step list of implications. Not necessarily processed in strict sequence, the list involves deduction from a constructed ad hoc category of people who make less-than-optimal incisions to surgeons in general, and from surgeons in general to 'that surgeon'. Her analysis of the mapping relations and blended imagery in (Grady et al. 1999) is replaced by a relevance-theoretic notion of category formation, characterized as the 'adjustment' of an initial encoded concept and a process of deductive reasoning meant to 'derive a set of implications that may help to satisfy [the hearer's] expectations of relevance' (2007: 106).

It is not entirely obvious why Vega Moreno abandons the idea of blended spaces altogether. One might suppose that, adapted to her relevance-theoretic framework, it might help explain the proposed process of conceptual adjustment. ${ }^{46}$ Neither does she make clear exactly how the ad hoc concept BUTCHER* yields the intended meaning. She says only that (2007: 111): 'the inferential process may

\footnotetext{
45 Each category is represented by a lexeme marked with an asterisk and written in capital letters.

achieving a broader and more realistic theory of metaphor' (2009. 276) by bringing together research from different disciplines with overlapping research goals. He presents a hybrid theory integrating relevance theory, $\mathrm{CIT}$, and CMT. As he points out, relevance theory has yet to offer any suggestion as to how the ad hoc concepts it proposes are formed or how mutual adjustment of lexical content, explicatures, and implicatures occurs. Similarly, CMT offers no suggestions about the conditions determining which elements from a source domain are mapped to a target domain' (2009: 287); generally speaking, it has paid insufficient attention to pragmatic aspects of metaphor use as well as the creation and interpretation of metaphors that do not instantiate any underlying conceptual metaphor. Tendahl sees advantages to integrating these three theoretical frameworks not least for the interest all of them take in the online processing of metaphor. He finds the network model well-suited to capture 'the dynamics of the ways in which different kinds of linguistic and contextual information interact' (2009: 286). Though I agree with the overall sentiment, problems persist in the merger including, I think, atomistic use of mental spaces (see Section 5.5, where each lexical concept acquires its own mental space). Other problems include a missing semantic dimension to the analysis of relevance in relation to interpretation of meaning, and an enduring belief in the explanatory power of ad hoc concepts and metaphorical lexical concepts that already have metaphorical meaning when applied in analysis. Among other examples, Tendahl analyses parts of a speech by Tony Blair employing strikingly metaphorical language: '...we have launched an unprecedented crusade to raise [educational] standards" (2009: 249). He rightly notes the impression of enhanced force emerging from the blend of political action and an 'unprecedented crusade' but does not explain how that impression emerges. Furthermore, the derivative lexical concept CRUSADE2 (CRUSADE1 being a literal crusade) - including 'assumptions about campaigns, political/religious/social change, etc.' (2009: 256) - presupposes the very metaphoricity it seeks to explain.
} 
involve several steps, which take the constructed ad hoc concept further and further away from the encoded concept ....' Metaphorically speaking, the concept is taken 'further and further away' by 'following a path of least effort'. Why does this happen?... simply to 'yield appropriate implications'. One reads that the 'adjustment' inferentially warrants implications that help satisfy the hearer's expectations of relevance; but no semantic analysis ensues. Her repeated references to adjustment begin to appear formulaic and still do not explain how these implications are derived. ${ }^{4}$

\section{THE RELEVANCE OF METAPHOR}

In Vega Moreno's relevance-theoretic account of metaphor, ad hoc concepts may highlight similarities between concepts; or, as in the case of the butchering surgeon or the bulldozing boss ("my boss is a bulldozer'), they may exclude all members of the original, non-metaphorical category. Thus, the 'butcher' category can represent brutality and the 'bulldozer' category insensitivity, despite there being no insensitive bulldozers and no butchers that are unethical or incompetent by virtue of being butchers. '...The resulting ad hoc category may exclude certain members of the denotation of the encoded concept. In other cases, it may exclude all the members of the denotation of the encoded concept, so that the literal referent of the metaphor vehicle is not only not a prototypical member of the resulting ad hoc category, but not a member at all...' (Vega Moreno 2007: 126-127). The ad hoc category BULLDOZER*, said to develop unconsciously in interpreting the metaphor 'my boss is a bulldozer', denotes neither bulldozers nor bulldozer attributes nor any inanimate entity, but people who are 'disrespectful, obstinate, undermine other people's feelings and thoughts, etc.' (2007: 97)

That the entities the encoded concept normally denotes fall outside the denotation of the new, ad hoc concept is not regarded as a problem. 'Because the encoded concept is merely a starting point for inference, there is no reason why it should not be adjusted to a point where the entities it is normally used to denote fall outside the denotation of the new ad hoc concept that results' 2007: 105). The ad hoc category is to be thought of as a class or set to which the target belongs; the boss in question thus belongs to 'a set of people who are insensitive to the feelings of others, ignore their suggestions and objections, are fixated on their own goals at the expense of others, are a danger to those who oppose them, etc.' (2007: 112) It remains unclear on what grounds Vega Moreno deems it plausible that the conceptualizer must conceive of a set including the boss as only one among many members, never mind how the conceptualizer derives this alleged meaning. That the conceptualizer follows a "path of least effort' ( $c f$. Sperber \& Wilson 2008) seems to me an insufficient answer.

\footnotetext{
In the course of just a few pages (2007: 106-108), she makes up to seven references to adjustment warranting the derivation of a set of implicatures to help satisfy the hearer's expectation of relevance - leaving the reader increasingly curious as to the cognitive process by which this is achieved. As Tendahl notes (2009: 153): 'according to relevance theory, we should assume that for butcher we create an ad hoc concept butcher* the denotation of which should encompass surgeons. However, we still do not know how we can extend the denotation of "butcher" in a way that surgeons are captured and the notion of incompetence is included.... Often the gap between a lexical concept and an ad-hoc concept cannot be accounted for theory-internally in relevance theory.'
} 
Vega Morena intends that a process of adjustment accounts for the transition: '.. the concept conveyed by the word "butcher" [and similarly by the word "bulldozer"] is continuously adjusted in order to warrant the derivation of these implicatures' (2007: 104-105). It remains a mystery how this adjusted category comes into being. The process happens behind closed curtains, so to speak; the hearer may only come to know the novel category after the fact: i.e., after having arrived at the result. '...It is important to bear in mind, that the hearer of the utterance does not find out what the actual denotation of the concept BUTCHER* constructed during the interpretation process would be until he arrives at an interpretation... which satisfies his expectations of relevance' (2007: 103).

Since Vega Moreno suggests no retrospective reconstruction to shed light on the conceptual process entailed by the adjustment, the semantics of the interpretation process, leading to satisfied expectations of relevance, remains obscure. The interjection of the adjustment process - constrained by the general regulatory mechanisms of relevance ${ }^{48}-$ is meant to ease dissatisfaction with the nearmagical emergence of metaphorical meaning attributed to CIT and blending theory, among other interaction theories $^{49}$; but one is left with the unanswered question, as Tendahl and Gibbs (2008: 1839) point out, 'why a physical attribute can acquire a psychological sense'.

Vega Moreno aspires to an account of metaphor that does not require any alignment of or mapping between domains. Nevertheless, elements and attributes are aligned and compared. In the case of the butcher-surgeon metaphor, the necessary 'pragmatic fine-tuning' is hypothesized to involve inferential steps (f) and (g): (f) 'a butcher cuts dead meat in a way that falls far short of the high levels of precision, delicacy, foresight and planning to avoid risk required in a competent surgeon', (g) 'the surgeon is a BUTCHER* (where BUTCHER* denotes people who make incisions in a way that falls far short of the levels of precision, delicacy, foresight and planning to avoid risk required in a competent surgeon)' (Vega Moreno 2007: 102) How are these inferential steps arrived at? How does the butcher come to be evaluated as a surgeon (his method "falls short")?

The style of analysis precludes justification. No procedure is indicated for countering or confirming particular analyses; one can only try to ascertain whether they are internally coherent. Methodologically speaking, the empirical dimension is replaced by a logical-inferential one. From a standpoint of cognitive processing and communicative relevancethe theory lacks an epistemic - and

\footnotetext{
${ }^{48}$ Compare Sperber and Wilson's (2008) deflationary claim that metaphor is 'nothing but looseness', arrived at 'in exactly the same way as literal, loose and hyperbolic interpretations: there is no mechanism specific to metaphors, and no interesting generalisation that applies only to them' (2008: 84). 'It is just that, on the whole, the closer one gets to the metaphor end of the literal/loose/metaphorical continuum, the greater the freedom of interpretation left to hearers or readers, and the more likely it is that relevance will be achieved through a wide array of weak implicatures, i.e. through poetic effects. So when you compare metaphors to other uses of words, you find a bit more of this and a bit less of that, but nothing deserving of a special theory, let alone a grand one' (2008: 103) The authors wish to extend their theory to account for poetic effects not just in speech but in literary texts as well. One question that comes to mind, somewhat - though not entirely - off topic, is how a theory hinging on the discourse interaction between speaker and hearer in online situations can deal with literary discourse, where meaning is created outside this kind of situationally grounded interaction.

Cf. Vega Moreno 2007: 73.
} 
indeed pragmatic - rationale for the proposed ad hoc categories to come into existence: what, in the process of meaning construction, prompts conceptualizers to construct these concepts? To take an example, the 'category' account of the butcher-surgeon metaphor (Example 1: 'Husband: I want that surgeon out of the hospital. That surgeon is a butcher!') introduces a whole group of surgeons into the inferential equation: 'surgeons who make incisions in a way that falls short of the levels of precision, delicacy, foresight and planning required may cause serious damage to someone in their care' (Vega Moreno 2007: 103). Yet the expression only makes reference to one particular surgeon; one wonders what warrants the evocation of surgeons in general. The speaker has no evident reason to relate the ovary-removing surgeon to a general class of people who botch jobs, etc. What makes such a broad category relevant for meaning construal? With no obvious semantic or pragmatic motivation, the category appears to be a purely analytic construct.

The ad hoc category BUTCHER* is similarly problematic. It 'denotes people who make incisions in a way that falls far short of the levels of precision, delicacy, foresight and planning to avoid risk required in a competent surgeon' (Vega Moreno 2007: 102) and, in yet more inclusive terms, 'the set of people who fall short of the standards of precision, delicacy and foresight required in making an incision, causing damage to humans beings in their care, and being liable for sanction as a result'. (2007: 105) 'The concept BUTCHER* as presented here [in a relevance-theoretic framework] would denote anyone (not necessary surgeons) who make cuts of this type' (2007: 103) Though inferentially useful in creating a valid deductive line of reasoning, it is hard to see why people other than butchers i.e. all "people" who make cuts of this type - would be relevant to consider.

In the case of the metaphorical bulldozing boss, an alternative analysis might conceive of 'removing obstacles in the way' not as a feature or attribute - REMOVE OBSTACLES IN THE WAY - but as a quasi-narrative scenario unfolding in the conceptualizer's imagination. A bulldozer - the 'vehicle' of the metaphor - removes obstacles in one's way. If this is the aspect that the situationally framed referential content (the boss) brings to the forefront, then the virtually represented blend of boss-and-bulldozer does something to the way in which the scenario, with the forceful boss, is seen in the mind's eye. Mappings of quasi-narrative - temporally dynamic - structure make the relevant topic structure stand out in vivid and exaggerated form, rendering the predicate more potent and emotionally evocative. The generic presentation of a bulldozer in action provides a force-dynamic framing the target scenario: presumably, the relation between employer and employee. The context provides a relevant, contextually motivated schema for evaluating the entity or relation in focus - the target scenario now framed by the relevant force dynamics of the source imagery - perhaps, in some interpretations, a social schema for evaluating specific types of interactions involving conflicting agendas, etc. In the mental space superposing the generic presentation onto the reference - the socalled 'blend' - the target is thus framed by the narrative force dynamics of the source and powered by its figural imagery: e.g., agent entity as bulldozer-boss, patient entity as inanimate run-over 'stuff' or human road kill. 
With its focus on the dynamic aspect of meaning - rather than encyclopaedic knowledge structures - this kind of phenomenological description represents a relevance-oriented alternative to accounts positing the ad hoc invention of superordinate categories such as the 'butcher' category of 'people who botch jobs in reprehensible and often appalling ways' (Glucksberg 1998: 42); or, in Sperber \& Wilson's analysis (2008: 97), the category identified as BUTCHER* 'denoting people who treat flesh in the way that butchers do' - or, in Vega Moreno's (2007: 105) more intricate analysis, the category that 'denotes the set of people who fall short of the standards of precision, delicacy and foresight required in making an incision, causing damage to human beings in their care, and being liable for sanction as a result'.

The force-dynamic description helps explain what is cognitively gained by the use of metaphorical expressions. Furthermore, it addresses Vega Moreno's concern (2007: 136) that 'if comprehension involves an interaction or mapping between two domains, there is a risk of circularity: the properties which the topic helps select in the vehicle are the properties attributed to the topic by the vehicle'. The metaphorical blend exposes a correlation between the force-dynamic structure in the blend of 'source' and 'target' inputs, with the effect of an experienced difference in the intensity of force. ${ }^{50}$ On this hypothesis, the emotional potency of metaphor is due to the experienced intensification of force in the target input when seen as the source: in the blend, the one virtually is the other, creating a hyperbolic effect. The force-dynamic intensification and the accompanying imagery supporting it explain the expressive advantages, both in communication and inner dialogue. The more strongly experienced both the force-dynamic and figural aspects of a metaphorical scenario are, the more evocative the metaphor. ${ }^{51}$

\section{CONCLUDING DISCUSSION}

Since the beginning, the nature and development of concepts has been a significant focal point in cognitive semantics, and with good reason. The distinctive characteristics of categorization and conceptualization are basic to any subject matter relating to human cognition, not least language shown to directly depend on the inner workings of just these phenomena. ${ }^{52}$ With mental space theory, a theory appeared that could encompass, in its scope of research data, the vast realm of human expressivity - including multimodal, diversely expressive phenomena like visual art, advertisement,

\footnotetext{
50 For more on the force-dynamic aspect of metaphor, see the discussion of the digging-your-own-grave metaphor in (Brandt 2013: Section 3.1.3). The proposed analysis of gravedigging expressions provides a methodological alternative to Coulson's (2001: 168-172) and Fauconnier and Turner's (2002: 131-135) 'reverse causality' account, as well as to the vision put forth in (Ruiz de Mendoza Ibáñez 1998: 273): '...a vision of blended spaces as a by-product of the activity of working memory where matched productions retrieved from production memory are executed to yield pre-established combinations of ICMs [Idealized Cognitive Models]'. ${ }^{51}$ (Brandt 2013: Section 3.1.2) offers an in-depth semantic analysis of the butcher-surgeon metaphor.

52 For me, the perspective Lakoff offers in Women, Fire, and Dangerous Things (1987) was something of a revelation: see e.g. Lakoff's discussion of Rosch's development of a radial theory of categorization.
} 
and literary conceit; in addition to addressing the more traditional linguistic interest in isolated sentences, increasingly reframed in terms of their potential appearance in utterances. Lakoff and Turner (1989) - who later diverged, assuming roles as primus motor in the development of NTL and CIT respectively - in this earlier work turn their attention from everyday to literary language, showing how the same conceptual metaphors underlying conventional language play a role in the conceptual structuring of poetic texts and other artifices of the imagination not governed by ordinary pragmatic objectives. Turner's enterprise of uncovering the 'literary mind' and Fauconnier's efforts to improve on contemporary philosophy of language have led to a semantic theory offering important insights. From blending analyses of textual excerpts and other sorts of material - e.g., pictorial - CIT developed the hypothesis that metaphorical meaning emerges in conceptual amalgamation of disparate representational contents in a blended space: 'the power and even the existence of central inferences of the projection come not from the source input space and not from the target input space but only from the blended space' (Turner 1996: 62). Analysis of the butcher-surgeon and bulldozing-boss examples validate this point.

In CMT, metaphors have a semantic motivation. Similarly, CIT takes a semantic stance, approaching linguistic phenomena from a psychologically mentalist - rather than, say, behavioural, computational or neuroscientific - point of view. ${ }^{53}$ Despite the stated hypothesis of a correspondence between mental and neural mappings - 'we think of the lines in [the Basic Diagram] (lines that represent conceptual projections and mappings) as corresponding to neural coactivations and bindings' (Fauconnier \& Turner 2002: 46) - CIT remains, for all intents and purposes, a semantic theory. Consequently, a 'good' blend is defined on semantic grounds, in terms of its effectiveness in expressing an idea, the degree of compression achieved, its adaptability, etc.

The term 'correspondence' is equivocal: does it imply the auxiliary co-occurrence of neural activity or actual identification? This presents something of a Pandora's box. ${ }^{54}$ Methodologically speaking, however, the theory is primarily analytical and intuitive, seeking inspiration and suggestive support rather than falsifying or verifying evidence from neuroscience.

NTL - CMT's offspring, developed in the 1990s and onwards (see e.g. Lakoff \& Johnson 1999, especially chapters 3-6) - is a neural theory striving to develop a computational model of metaphor: more specifically, of primary metaphors. These are not interpretational but a matter of immediate conceptual mapping via neural connections (Lakoff \& Johnson 1999: 57). Primary metaphors are building blocks of other kinds of metaphors; and thus, ultimately, metaphoricity is part of the 'cognitive unconscious': an unconscious that, in the spirit of Locke, originates in sensorimotor

\footnotetext{
${ }^{53}$ The same can be said of other cognitive linguists mentioned in this paper: e.g., Talmy, Langacker, and Sweetser.

${ }^{54} \mathrm{CIT}$ 's failure to state its position clearly is a likely contributing factor motivating Lakoff's criticism of it for not taking sufficient interest in modeling neural correlates.
} 
experience from which all subjective experience derives ( $c f$. the empiricist dictum that nothing is in the intellect that was not first in the senses).

A shift seems to have occurred, placing principal explanatory power in computational modeling of hypothesized neural activity - in consequence, putting aside, or even negating, the experiential dimension of conceptualization. 'Good blends' - as explained in Lakoff's comparison of theories in a discussion on the cogling mailing list (August 2005) ${ }^{55}$ - arise from neural optimization. Lakoff explains that blending is just neural binding: a claim based on experimental evidence from the study of primary metaphor (e.g., the conceptualization of quantity in terms of verticality: MORE IS UP). Cooccurrence in experience is simultaneous activation of brain regions. Experiential conflation has no semantic motivation and is solely identified as simultaneous activation of distinct parts of the brain. Frames or domains experienced together are temporally neurally bound: they fire in synch. Neural coactivation is activation flowing along neural connections between distinct brain regions, stimulating synapses to change chemically and grow stronger. The 'mapping' in metaphor is neural circuitry strengthened and made permanent. Multiple mappings across roles in different frames are identified as neural circuits connecting distinct brain regions. Different frames equals different parts.

I am not sure how the step from the schematic mappings of so-called primary metaphor to the more complex material analyzed in CIT is supposed to be accounted for so as to lead to the conclusion that all blends - including expressive ones - are simply neural bindings. It is not obvious how one would proceed, for instance, in investigating why a representation of a surgeon and the concept of butcher would fire in synch. Nor is it obvious how the predicative directionality comes about. The equating of conceptual integration with neural binding seems highly dubious as a proposition about semantic structure. If accepted though, it is understandable why designing integration diagrams appears curiously far removed for Lakoff from what needs to be done.

To address the issue of methodology, one should first consider what can conceivably be gained: what kind of insight is one after? What does one want to know? One must also look at what is technically possible, given the developmental state of contemporary neuroscience. While it seems clear that some categories - e.g., human faces - are localized, it is questionable whether in fact there are 'parts' corresponding to every semantic frame or category. It is not even clear whether every concept activated is necessarily localized, nor how mental enactments of meaning play out neurally. Are all semantic frames and categories to be conceived of as localizable circuits? If so, do these show up for observation simply as activity? ${ }^{56}$ Perhaps the notions of 'domain' and 'frame' are becoming synonymous with 'parts of the brain'. This would seem a rather nebulous substitution though, reducing consciously discernible semantic entities to their identification as activity in general regions of the

\footnotetext{
${ }^{55}$ http://listserv. linguistlist.org/cgi-bin/wa? A2=indo508\&L=cogling\&D=1\& $\mathrm{T}=0 \& \mathrm{P}=11634$ (accessed 22 August 2013).

${ }^{56}$ This would appear particularly problematic as a motivating assumption for investigative methods if more entrenchment actually reflects less activity, due to less cognitive effort - meaning that less neural processing is required.
} 
brain. Whatever the case may be, the observation that two general parts of the brain are active at the same time hardly constitutes a semantic analysis of meaning construction. What is missing is recognition of the expressive function of metaphorical concepts and language in communication: for whom do these concepts and expressions exist if not the communicative minds that put them on stage in real-life situations?

If mappings equate to neural circuitry and permanent mappings to strengthened neural circuitry, the question remains: what is it about those mappings that makes them durable? What, besides recurrence - durability, entrenchment - might still make them successful? These are semanticpragmatic questions.

Obviously, people do not exchange bits of brain in order to communicate. There is another, less tangible dimension to meaning not captured by observations of how the brain works - or by computational models of how the brain might work. From a practical point of view, experientially informed descriptions of representations are a necessary component in any theory of semantic meaning: valuable in and of themselves and as an indispensible prerequisite for investigating their neural realization. In the most basic sense, one needs to know what to look for.

\section{REFERENCES}

Ask Larsen, F. (2003). The Washing-Smooth Hole-Fish and Other Findings of Semantic Potential and Negotiation Strategies in Conversation with Congenitally Deafblind Children. Unpublished MA thesis available as CNUS No. 9 at http://www.nordicwelfare.org. Aarhus, Denmark: Aarhus University.

Austin, J.L. (1962). How to Do Things with Words. Oxford: Oxford University Press.

Benveniste, É. (1966). Problèmes de linguistique générale. Paris: Gallimard.

Benveniste, É. (1971). Problems in General Linguistics: Miami Linguistics Series 8, Meek., M.E. (tr.). Coral Gables, FL, USA: University of Miami Press.

Brandt, L. (2013). The Communicative Mind. A Linguistic Exploration of Conceptual Integration and Meaning Construction. Cambridge Scholars Publishing.

Brandt, L. (2010). Language and Enunciation: A Cognitive Inquiry with Special Focus on Conceptual Integration in Semiotic Meaning Construction. Doctoral dissertation. Aarhus, Denmark: Aarhus University.

Brandt, L. (2008). A semiotic approach to fictive interaction as a representational strategy in communicative meaning construction. In Oakley, T. \& Hougaard, A. (eds.), Mental Spaces Approaches to Discourse and Interaction (109-148). Amsterdam: John Benjamins.

Brandt, L. \& Brandt, P.A. (2005). Making sense of a blend: A cognitive-semiotic approach to metaphor. In Ruiz de Mendoza Ibáñez, F.J. (ed.), Annual Review of Cognitive Linguistics 3 (216249). Amsterdam: John Benjamins. First published (2002) as Making sense of a blend, Apparatur, 4: 62-71. 
Brandt, P.A. (2004). Spaces, Domains, and Meaning: Essays in Cognitive Semiotics. Bern: Peter Lang.

Coulson, S. (2003). Reasoning and rhetoric: Conceptual blending in political and religious rhetoric. In Oleksy, E. \& Lewandowska-Tomaszczyk, B. (eds.), Research and Scholarship in Integration Processes (59-88). Lodz, Poland: Lodz University Press.

Coulson, S. (2001). Semantic Leaps: Frame-Shifting and Conceptual Blending in Meaning Construction. Cambridge, UK: Cambridge University Press.

Coulson, S. (1996). The Menendez Brothers Virus: Analogical mapping in blended spaces. In Goldberg, A. (ed.), Conceptual Structure, Discourse, and Language. Stanford, CA, USA: CSLI publications.

Coulson, S. \& Oakley, T. (2005). Blending and coded meaning: Literal and figurative meaning in cognitive semantics. Journal of Pragmatics, 37(10):1510-1536.

Coulson, S. \& Oakley, T. (2003). Metonymy and conceptual blending. In Panther, K.-U. \& Thornburg, L.L. (eds.), Metonymy and Pragmatic Inferencing (51-79). Amsterdam: John Benjamins.

Fauconnier, G. (1997). Mappings in Thought and Language. Cambridge, UK: Cambridge University Press.

Fauconnier, G. (1994 [1985]). Mental Spaces: Aspects of Meaning Construction in Natural Language. Cambridge, UK: Cambridge University Press.

Fauconnier, G. \& Turner, M. (2002). The Way We Think: Conceptual Blending and the Mind's Hidden Complexities. New York: Basic Books.

Fauconnier, G. \& Turner, M. (1999). Analysis versus global insight: How and why do we blend cause and effect? University of California, Berkeley, 2005. Notes from The Way We Think: Conceptual Blending and the Mind's Hidden Complexities. New York: Basic Books (2005). Available online from http://markturner.org/ucbhandout.rtf.

Fauconnier, G. \& Turner, M. (1998). Conceptual integration networks. Cognitive Science, 22 (2): 133187.

Fauconnier, G. \& Turner, M. (1996). Blending as a central process of grammar. In Goldberg, A. (ed.), Conceptual Structure, Discourse and Language (113-129). Stanford, CA, USA: CSLI publications.

Fauconnier, G. \& Turner, M. (1995). Conceptual integration and formal expression. Journal of Metaphor and Symbolic Activity, 10(3): 183-203.

Fauconnier, G. \& Turner, M. (1994). Conceptual Projection and Middle Spaces: Report 9401, Department of Cognitive Science. La Jolla, CA, USA: University of California San Diego.

Feldman, J. \& Narayanan, S. (2004). Embodied meaning in a neural theory of language. Brain and Language 89: 385-392.

Fernandez-Duque, D. \& Johnson, M. (1999). Attention metaphors: How metaphors guide the cognitive psychology of attention. Cognitive Science 23: 83-116. 
Gallagher, S. (2009). Philosophical antecedents to situated cognition. In Robbins, P. \& Aydede, M. (eds.), Cambridge Handbook of Situated Cognition (35-51). Cambridge, UK: Cambridge University Press.

Gallagher, S. (2009b). Two problems of intersubjectivity. Journal of Consciousness Studies 16(6-8): 289-308.

Gallagher, S. (2008). Neural simulation and social cognition. In Pineda, J.A. (ed.), Mirror Neuron Systems: The Role of Mirroring Processes in Social Cognition (355-71). Totowa, NJ, USA: Humana Press.

Gallagher, S. (2007). Logical and phenomenological arguments against simulation theory. In Hutto, D. \& Ratcliffe, M. (eds.), Folk Psychology Re-assessed (63-78). Dordrecht: Springer.

Gallagher, S. (2001). The practice of mind: Theory, simulation, or interaction? Journal of Consciousness Studies, 8(5-7): 83-107.

Gallese, V. (2007). Mirror neurons and the social nature of language: The neural exploitation hypothesis. Social Neuroscience 3(3): 317-333.

Gallese, V. (2005). Embodied simulation: From neurons to phenomenal experience. Phenomenology and the Cognitive Sciences 4: 23-48.

Gallese, V. \& Lakoff, G. (2005). The brain's concepts: The role of the sensory-motor system in conceptual knowledge. Cognitive Neuropsychology, 22(3-4): 455-479.

Gibbs, Jr., R.W. (2000). Making good psychology out of blending theory. Cognitive Linguistics 11(34): $347-358$.

Glucksberg, S. (2001). Understanding Figurative Language: from Metaphors to Idioms. Oxford: Oxford University Press.

Glucksberg, S. (1998). Understanding metaphor. Current Directions in Psychological Science, 7(2): $39-43$.

Glucksberg, S. \& Keysar, B. (1990). Understanding metaphorical comparisons: Beyond similarity. Psychological Review, 97(1): 3-18.

Grady, J., Oakley, T. \& Coulson, S. (1999). Conceptual blending and metaphor. In Steen, G. \& Gibbs, Jr., R.W. (eds.), Metaphor in Cognitive Linguistics: Selected Papers from the Fifth International Cognitive Linguistics Conference, Amsterdam, July 1997 (101-124). Amsterdam: John Benjamins.

Grice, H.P. (1968). Utterer's meaning, sentence meaning, and word-meaning. Foundations of Language, 4: 225-242.

Harder, P. (2010). Meaning in Mind and Society: A Functional Contribution to the Social Turn in Cognitive Linguistics. Berlin: Mouton de Gruyter.

Hougaard, A. (2005). How're We Doing: An Interactional Approach to Cognitive Processes of Online Meaning Construction. Doctoral dissertation. Odense, Denmark: University of Southern Denmark. 
Johnson, M. \& Lakoff, G. (2002). Why cognitive linguistics requires embodied realism. Cognitive Linguistics 13(3): 245-263.

Kövecses, Z. (2011). Recent developments in metaphor theory: Are the new views rival ones?Review of Cognitive Linguistics. Special issue on Metaphor and Metonymy Revisited Beyond the Contemporary Theory of Metaphor: Recent Developments and Applications, 15: 11-25.

Lakoff, G. (2008). The neural theory of metaphor. In Gibbs, Jr., R.W. (ed.), The Handbook of Metaphor and Thought (17-38). New York: Cambridge University Press.

Lakoff, G. (1996). Sorry, I'm not myself today: The metaphor system for conceptualizing the self. In Fauconnier, G. \& Sweetser, E. (eds.), Spaces, worlds and grammar (91-123). Chicago: University of Chicago Press.

Lakoff, G. (1993). The contemporary theory of metaphor. In Ortony, A. (ed.), Metaphor and Thought (202-251). Cambridge, UK: Cambridge University Press.

Lakoff, G. (1987). Women, Fire, and Dangerous Things: What Categories Reveal About the Mind. Chicago: University of Chicago Press.

Lakoff, G. \& Johnson, M. (1999). Philosophy in the Flesh: The Embodied Mind and Its Challenge to Western Thought. New York: Basic Books.

Lakoff, G. \& Johnson, M. (1980). Metaphors We Live By. Chicago: University of Chicago Press.

Lakoff, G. \& Turner, M. (1989). More than Cool Reason: A Field Guide to Poetic Metaphor. Chicago: University of Chicago Press.

Langacker, R.W. (2002). Deixis and subjectivity. In Brisard, F. (ed.), Grounding: The Epistemic Footing of Deixis and Reference (1-28). Berlin: Mouton de Gruyter.

Langacker, R.W. (1999). Virtual reality. Studies in the Linguistic Sciences, 29(2): 77-103.

Langacker, R.W. (1987). Foundations of Cognitive Grammar, Vol. 1: Theoretical Prerequisites. Stanford, CA, USA: Stanford University Press.

McNeill, D. (2005). Gesture and Thought. Chicago: University of Chicago Press.

Pascual, E. (2008). Fictive interaction blends in everyday life and courtroom settings. In Oakley, T. \& Hougaard, A. (eds.), Mental Spaces Approaches to Discourse and Interaction (79-107). Amsterdam: John Benjamins.

Pascual, E. (2006). Fictive interaction within the sentence: A communicative type of fictivity in grammar. Cognitive Linguistics 17(2): 245-267.

Pascual, E. (2002). Imaginary Trialogues: Conceptual Blending and Fictive Interaction in Criminal Courts. Utrecht: LOT.

Rohrer, T. (2007). The body in space: Embodiment, experientialism and linguistic conceptualization. In Ziemke, T., Zlatev, J., Frank, R. \& Dirven, R. (eds.), Body, Language and Mind, Vol 1 (339378). Berlin: Mouton de Gruyter.

Ruiz de Mendoza Ibáñez, F.J. (1998). On the nature of blending as a cognitive phenomenon. Journal of Pragmatics, 30(3): 259-274. 
Searle, J.R. (1969). Speech Acts: An Essay in the Philosophy of Language. Cambridge, UK: Cambridge University Press.

Sperber, D. \& Wilson, D. (2008). A deflationary account of metaphors. In Gibbs, Jr., R.W. (ed.), The Handbook of Metaphor and Thought (84-105). New York: Cambridge University Press.

Sperber, D. \& Wilson, D. (1995). Postface to the second edition, Relevance: Communication and Cognition. Oxford: Basil Blackwell.

Sperber, D. \& Wilson, D. (1986). Relevance: Communication and Cognition. Oxford: Basil Blackwell.

Sweetser, E. (1990). From Etymology to Pragmatics: Metaphorical and Cultural Aspects of Semantic Structure. Cambridge, UK: Cambridge University Press.

Talmy, L. (2000). Toward a Cognitive Semantics, Vol. 1 \& II. Cambridge, MA, USA: MIT Press.

Tendahl, M. (2009). A Hybrid Theory of Metaphor: Relevance Theory and Cognitive Linguistics. London: Palgrave Macmillan. Doctoral dissertation (2006), University of Dortmund, Germany.

Tendahl, M \& Gibbs, Jr., R.W. (2008). Complementary perspectives on metaphor: Cognitive linguistics and relevance theory. Journal of Pragmatics, 40(11): 1823-1864.

Thompson, E., \& Varela, F. (2001). Radical embodiment: Neural dynamics and consciousness. Trends in Cognitive Sciences, 5(10): 418-425.

Tomasello, M. (2006). The social-cognitive bases of language development. In Brown, K. (ed.), Encyclopedia of Language \& Linguistics: Second Edition. Amsterdam: Elsevier.

Tower, W. (2004). Everything ravaged, everything burned. In Marcus, B. (ed.), The Anchor Book of New American Short Stories. Anchor Books.

Trevarthen, C. (1999). Intersubjectivity. In Wilson, R. \& Keil, F. (eds.), The MIT Encyclopedia of Cognitive Sciences (413-416). Cambridge, MA, USA: MIT Press.

Trevarthen, C. (1995). Contracts of mutual understanding: Negotiating meaning and moral sentiments with infants. In Wohlmuth, P. (ed.), The Crisis of Text: Issues in the Constitution of Authority, San Diego, CA, USA: Unversity of San Diego School of Law. First appearing (1995) in Journal of Contemporary Legal Issues, 6: 373-407.

Trevarthen, C. (1994). Infant semiosis. In Noth, W. (ed.), Origins of Semiosis (219-252). Berlin: Mouton de Gruyter.

Turner, M. (1996). The Literary Mind: The Origins of Thought and Language. Oxford: Oxford University Press.

Turner, M. (1991). Reading Minds: The Study of English in the Age of Cognitive Science. Princeton, NJ, USA: Princeton University Press.

Turner, M. \& Fauconnier, G. (2003 [2000]). Metaphor, metonymy, and binding. In Barcelona, A. (ed.), Metaphor and Metonymy at the Crossroads: A Cognitive Perspective (133-145), Berlin: Mouton de Gruyter. Also appearing in Dirven, R. \& Pörings, R. (eds.) (2002). Metaphor and Metonymy in Comparison and Contrast (469-487). Berlin: Mouton de Gruyter. 
Turner, M. \& Fauconnier, G. (1999). A mechanism of creativity. Poetics Today, 20(3): 397-418.

Turner, M. \& Fauconnier, G. (1995). Conceptual integration and formal expression. Journal of Metaphor and Symbolic Activity, 10(3): 183-204.

Urban, W. (1939). Language and Reality. London: G. Allen and Unwin, Ltd.

Vega Moreno, R.E. (2007). Creativity and convention: The pragmatics of everyday figurative speech. Amsterdam: John Benjamins.

Willems, R.M., Tonil, I., Hagoort, P. \& Casasanto, D. (2009). Neural dissociations between action verb understanding and motor imagery. Journal of Cognitive Neuroscience, 22(10): 2387-2400.

Zlatev, J. (2008). From proto-mimesis to language: Evidence from primatology and social neuroscience. Journal of Physiology, 102: 137-151.

Zlatev, J., Racine, T., Sinha, C. \& Itkonen, E. (eds.) (2008). The Shared Mind: Perspectives on Intersubjectivity. Amsterdam: John Benjamins. 


\title{
Vyvyan Evans
}

\author{
Bangor University
}

\section{Metaphor, Lexical Concepts, and Figurative Meaning Construction}

\begin{abstract}
This paper addresses the status and significance of conceptual metaphor as an explanatory theoretical construct giving rise to figurative language. While conceptual metaphor has sometimes been presented as the most important element in this process (e.g., Lakoff 2008; Lakoff \& Johnson 1999), I argue that conceptual metaphor is but one component - albeit a significant one - in figurative meaning construction. I contend that, while conceptual metaphors inhere in the conceptual system, there is a class of metaphor discourse metaphor - that emerges and evolves in and through language use and inheres in the linguistic system. Indeed, the cognitive units associated with discourse metaphors and other linguistic expressions I refer to as lexical concepts. I introduce LCCM theory (Evans 2009b, 2010b, 2013) and suggest that lexical concepts provide access to non-linguistic knowledge representations - cognitive models - which can be structured in terms of conceptual metaphors. One aim of LCCM theory is to provide an account of the role of conceptual metaphors and the way they interact with other types of linguistic and conceptual knowledge structures in figurative meaning construction. The paper illustrates how lexical concepts in figurative meaning construction facilitate access both to conceptual metaphors and a specific type of inference - semantic affordances (Evans 2010b) - which arise from cognitive models. It is the combination of these types of knowledge representation that give rise to figurative meaning construction in the examples considered here, rather than conceptual metaphors alone. This perspective provides, I suggest, the promise of building towards a joined-up account of figurative meaning construction.
\end{abstract}

Keywords: Conceptual metaphor, Conceptual Metaphor Theory, lexical concept, discourse metaphor, LCCM theory, figurative language construction, semantic affordance.

\section{INTRODUCTION}

Since the 1980 publication of Metaphors We Live By, Conceptual Metaphor Theory (CMT) has proved to be extremely influential. However, over thirty years on, it is also clear that, while important, the significance of conceptual metaphor as an explanatory theoretical construct has sometimes been overstated by Lakoff and his closest collaborators. For one thing, early works in the CMT tradition sought - or at least were perceived as seeking - to supplant significant intellectual traditions dealing with metaphor and, in particular, their explanations for metaphor as a phenomenon. It has become clear that CMT in fact addresses a type of phenomenon that, in large measure, had not been studied or even recognized previously. In contrast, a large set of figurative-language data dealt with in other traditions including philosophy of language and psycholinguistics are barely addressed by conceptual 
metaphor researchers. One of my aims in the present paper, addressed in detail in Section Two, is to tease out what is special about conceptual metaphor and what it cannot account for.

A second tendency in the CMT tradition has been to suggest that conceptual metaphors might be central to core issues relating to language qua system. These have included language change and the issue of polysemy. However, a close examination of the linguistic evidence suggests that conceptual metaphor may not be the root cause of either of these phenomena. In Section 3, I examine the claim that conceptual metaphor drives these processes and argue, on the contrary, that usage-based issues play a more central role. I argue that conceptual metaphors do not directly motivate language use. That said, conceptual metaphors remain important for language understanding. Specifically, they may serve as top-down constraints ${ }^{1}$ on aspects of language change and the emergence of polysemy.

Finally, one of the issues that has received increased attention in recent years in (cognitive) linguistics relates to meaning construction. It has become clear that well-articulated accounts of figurative language understanding, while involving conceptual metaphors, also require an account of how conceptual metaphors interface with meaning construction mechanisms: for instance, as identified under the aegis of Conceptual Blending Theory (BT: e.g., Coulson 2000; Fauconnier \& Turner 2002). Another key issue relates to the role that language plays in (figurative) meaning construction. This is an issue I address in Section 4. In particular, I discuss the role that a recent theoretical model, LCCM theory (Evans 2006, 2009b, 2010b, 2013), plays in modelling the contribution of conceptual metaphors, other conceptual representations, and language in metaphor interpretations. I have suggested elsewhere (Evans 2010b, 2013) that LCCM theory is continuous with BT, providing the first detailed means of modelling composition: one of the key mechanisms associated with conceptual integration.

By way of overview, the three main sections of the paper - detailed below - make three specific claims:

- $\quad$ CMT provides an account of just one type of the cognitive representations that must be in play in figurative language understanding. While conceptual metaphors may underpin certain types of figurative language, there are classes of linguistic metaphors that appear to be motivated in ways that are, at least in part, independent of conceptual metaphors.

- Those conceptual metaphors that motivate language use do not do so in an isomorphic way. That is, while conceptual metaphors are invariably activated by instances of language use that draw on them, language is a distinct semiotic system with a level of semantic representation independent of conceptual metaphors and other representations

\footnotetext{
${ }^{1}$ Zlatev (2011) makes a similar point.
} 
which inhere in the conceptual system. These I refer to as lexical concepts ${ }^{2}$ (2006, 2009b, 2010b, 2013). The deployment and development of lexical concepts is central to issues such as semantic change in language and in giving rise to the proliferation of new word meanings: the issue of polysemy.

- An account of figurative meaning construction requires a generalized theory of conceptual integration. Recognizing the psychological reality of conceptual metaphors does not, in and of itself, provide an account of how figurative meaning arises, as mediated by language use. In addition, the analyst requires an understanding of various knowledge types that are implicated in figurative language understanding and use. This includes the language-specific level of semantic representations - lexical concepts - and how they are combined. Also required is an understanding of the range of conceptual metaphors that inhere in the conceptual system and how these are combined, via (something akin to) conceptual blending, as studied by Coulson (2000), Fauconnier and Turner (2002), Grady (2005) and others. Finally, also required is an account of how lexical concepts facilitate activation of conceptual metaphors and other types of conceptual knowledge structures - what I refer to as semantic affordances - in the construction of linguistically mediated figurative meaning. All of this involves a joinedup account of linguistic and conceptual integration mechanisms: a generalized theory of conceptual integration.

\section{CONCEPTUAL METAPHORS VERSUS DISCOURSE METAPHORS}

In this section I argue that the theoretical construct of the conceptual metaphor accounts for just a subset of linguistic metaphors, as manifested in figurative language. In particular, I argue for a disjunction between figurative language that in part - perhaps large part - is motivated by conceptual metaphors and figurative language that is motivated by what I shall refer to as discourse metaphors. The term 'discourse metaphor' is a theoretical construct introduced into the literature by Jörg Zinken (e.g., 2007). I shall adopt and nuance this construct as I proceed.

The essential distinction between conceptual metaphors and discourse metaphors is the following. Conceptual metaphors are independent of language but influence certain types of language use. In contrast, discourse metaphors are linguistically mediated instances of figurative language use. While they presumably have a conceptual basis, ${ }^{3}$ they arise in language use to address particular and often specific communicative needs and functions. Moreover, their status evolves as a function of language use such that they can become entrenched linguistic units independent of the conceptual mechanisms

\footnotetext{
${ }^{2}$ The lexical concept - as a theoretical construct - relates in LCCM theory to a level of cognitive representation that inheres in the linguistic system rather than the conceptual system. See Evans (2009b, in press) for further details on the distinction between the linguistic and conceptual systems.

${ }^{3}$ Gentner et al.'s (2001) proposals relating to analogical structure mapping can be interpreted as providing a set of suggestions for the conceptual basis of discourse metaphors.
} 
that may have given rise to them in the first place. This stands in contrast to instances of language use motivated by conceptual metaphor: language use of this type always activates the underlying conceptual metaphor which, crucially, remains (largely) unaffected by language use.

I begin by charting some key developments in the study of conceptual metaphor. I then argue that CMT initially attempted to provide an all-encompassing account of linguistic metaphor. However, due to a large body of linguistic data that simply could not be accounted for in a straightforward way under the aegis of CMT, more recently one prominent conceptual metaphor scholar (Grady 1999) has acknowledged that conceptual metaphor may be a knowledge type that is distinct from a range of other types responsible for linguistic metaphor. Following on from this, I adduce in detail the notion of the discourse metaphor and contrast it with the theoretical construct of the conceptual metaphor.

\subsection{An overview of conceptual metaphor theory}

In the earliest work in the CMT tradition - especially (Lakoff \& Johnson 1980, Lakoff \& Turner 1989, Lakoff 1993) - there was a tendency to claim, or at least to suggest, that linguistic metaphor was a consequence of conceptual metaphor. A conceptual metaphor was conceived in this early work as a series of asymmetric mappings stored in long-term memory uniting structure from a more concrete source domain to a more abstract target domain: as in, LOVE IS A JOURNEY. Until relatively recently, evidence for the existence of conceptual metaphor came primarily from language. The following examples, which derive from (Lakoff \& Johnson 1980), provide - it is claimed - evidence for the existence of such a conceptual metaphor:

(1) Look how far we've come. We're at a crossroads. We'll just have to go our separate ways. We can't turn back now. I don't think this relationship is going anywhere. Where are we? We're stuck. It's been a long, bumpy road. This relationship is a dead-end street. We're just spinning our wheels. Our marriage is on the rocks. This relationship is foundering.

According to Lakoff and Johnson, the expressions in (1) are all motivated by an entrenched pattern in the mind: a conceptual metaphor. The conceptual metaphor LOVE IS A JOURNEY is made up of a fixed set of well-established mappings (see Table 1). The mappings are fixed in the sense that there a set number of them. They are well-established in the sense that they are stored in long-term memory.

What these mappings do is structure ideas belonging to the more abstract domain of LOVE in terms of concepts belonging to the more concrete domain of JOURNEY. In the domain of LOVE, one has a number of different concepts. These include concepts for lovers, the love relationship, events that take place in the love relationship, difficulties that take place in the relationship, and progress one makes in resolving these difficulties and developing the relationship. One also has concepts for the choices about what to do in the relationship such as moving in together, whether to split up, and so on, and the shared and separate goals one might have for the relationship. 
Similarly, Lakoff and Johnson contend that people represent a range of concepts relating to the domain of JOURNEY. These include concepts for the travellers, the vehicle used for the journey plane, train, or automobile - the distance covered, obstacles encountered such as traffic jams that lead to delays and hence impediments to the progress of the journey, decisions about the direction and the route to be taken, and knowledge about destinations. The conceptual metaphor LOVE IS A JOURNEY provides a means of systematically mapping notions from the domain of JOURNEY onto corresponding ideas in the domain of LOVE. This means that ideas in the LOVE domain are structured in terms of knowledge from the domain of JOURNEY. For instance, the lovers in the domain of LOVE are structured in terms of travellers such that one understands lovers in terms of travellers. Similarly, the love relationship itself is structured in terms of the vehicle used on the journey. For this reason, one can talk about marriage foundering, being on the rocks, or stuck in a rut and understand expressions such as these as relating not literally to a journey but rather to two people in a long-term love relationship that is troubled in some way.

Moreover, it must be the case - so Lakoff and Johnson argue - that one has knowledge of the sort specified by the conceptual metaphor stored in one's head. If this were not so, one would not be able to understand these English expressions: to understand lovers in terms of travellers and the relationship in terms of the vehicles, and so on. The linguistic expressions provide an important line of evidence for the existence of the conceptual metaphor.

Table 1 summarizes the mappings that make up the conceptual metaphor. In Table 1, the arrow signals what is claimed to map onto what. For instance, the concept for travellers from the domain of JOURNEY maps onto the concept for lovers in the domain of LOVE. These corresponding concepts are thus established as paired concepts within the conceptual metaphor. It is because of this one can speak (and think) of lovers in terms of travellers.

\begin{tabular}{|l|c|l|}
\hline \multicolumn{1}{|c|}{ Source domain: JOURNEY } & Mappings & \multicolumn{1}{|c|}{ Target domain: LOVE } \\
\hline TRAVELLERS & $\rightarrow$ & LOVERS \\
\hline VEHICLE & $\rightarrow$ & LOVE RELATIONSHIP \\
\hline JOURNEY & $\rightarrow$ & EVENTS IN THE RELATIONSHIP \\
\hline DISTANCE COVERED & $\rightarrow$ & PROGRESS MADE \\
\hline OBSTACLES ENCOUNTERED & $\rightarrow$ & DIFFICULTIES EXPERIENCED \\
\hline DECISIONS ABOUT DIRECTION & $\rightarrow$ & CHOICES ABOUT WHAT TO DO \\
\hline DESTINATION OF THE JOURNEY & $\rightarrow$ & GOALS OF THE RELATIONSHIP \\
\hline
\end{tabular}

Table 1: Mappings for LOVE IS A JOURNEY. 
Since its advent, CMT has often been presented as a perspective that supplants what I will refer to as the received view of metaphor. The received view treats metaphor as primarily a literary/linguistic device in which comparisons highlight pre-existing - albeit potentially obscure - similarities between a target or tenor and a vehicle or base. This position, in which metaphor is conceived as a linguistic means for capturing perceived similarities, has a long and venerable tradition going back in the Western scholarly tradition to Aristotle's Poetics. The received view often associates metaphor with a specific form: the ' $\mathrm{X}$ is a $\mathrm{Y}$ ' or predicate nominative construction, as in (2):

(2) Dew is a veil.

In an example such as this, the received view holds that properties and relations associated with dew covering grass and a veil covering a woman's face are compared. In early work on linguistic metaphor in the psycholinguistic tradition, the conceptual process assumed to underlie metaphors such as this was that of feature mapping. In this process, properties belonging to different entities were compared and judged to be overlapping (Miller 1979, Ortony 1979, Tversky 1977). There is some empirical support for this view. For instance, the degree of similarity between tenor and vehicle concepts has been demonstrated as correlating with aptness and interpretability of linguistic metaphors (Johnson \& Malgady 1979; Malgady \& Johnson 1976; Marschark, Katz \& Paivio, 1983) as well as the processing time required to understand a linguistic metaphor (Gentner \& Wolff 1997).

However, Lakoff (1993) and his various collaborators, including Mark Johnson (Lakoff \& Johnson 1980) and Mark Turner (Lakoff \& Turner, 1989), argued vociferously against explanations for linguistic metaphor based on similarity. After all, when one conceptualizes love in terms of journeys, there is nothing objectively similar about the two. If two things are similar then, in principle, the tenor and vehicle should be equally adept at being deployed to understand the other. One would expect to find a symmetric or bi-directional process, along the lines advocated by e.g. Black (1979) in his interactional theory of metaphor. However, as Lakoff and Johnson and Lakoff and Turner showed, expressions relating to love and journeys are not symmetric in this sense. After all, while one can describe two newlyweds as having started on their journey and be understood as referring to the commencement of their married life together, one cannot refer to people starting out on a car journey as having just got married and be understood as referring to the car journey itself.

Central to the CMT account is the claim that conceptual metaphors are asymmetric, as reflected by the directionality of the arrows in Table 1: from the source to the target domain. Crucially, according to Lakoff, Johnson and Turner, what motivates the emergence of a conceptual metaphor, rather than similarity, is the nature of embodied experience. Conceptual metaphors are held to arise from tight and recurring correlations in experience. In the case of LOVE IS A JOURNEY, love is an instance of a purposeful activity. As journeys correlate with - indeed are instances of - purposeful activities, the LOVE IS A JOURNEY metaphor can be viewed as an instance of the more general conceptual metaphor: A PURPOSEFUL ACTIVITY IS A JOURNEY. 
In a more recent version of CMT, the experiential grounding of conceptual metaphor is formalized in terms of the theoretical construct known as a primary conceptual metaphor, or primary metaphor for short (Lakoff \& Johnson 1999; Grady 1997a, 1997b). Primary metaphors are hypothesized to be directly grounded in experience, arising from experiential correlations. They can be unified via the process of conceptual blending (Grady 1997b, 2005), giving rise to compound - or complex - conceptual metaphors, of which LOVE IS A JOURNEY is claimed as an instance. That is, LOVE IS A JOURNEY might arise via fusion of more fundamental - in the sense of directly grounded primary metaphors such as A PURPOSEFUL ACTIVITY IS A JOURNEY, STATES ARE LOCATIONS, and so on. LOVE IS A JOURNEY is vicariously grounded in experience, but the grounding is not direct as with primary metaphors.

In the most recent version of CMT, Lakoff (e.g., 2008) argues for a neural perspective on conceptual metaphor. He proposes that primary metaphors arise via mechanisms of Hebbian learning: correlations in experience give rise to correlated firing of neurons; what fires together wires together. It is for this reason that primary metaphors such as CHANGE IS MOTION (e.g., that species is going extinct), KNOWING IS SEEING (e.g., I see what you mean), and INTIMACY IS PROXIMITY (e.g., those two are still close, even after all these years) naturally arise cross-linguistically. They do so because they form fundamental recurring units (primary scenes in the parlance of Grady 1997a) of human experience.

\subsection{Correlation versus resemblance}

While many linguistic metaphors do indeed appear to be the result of conceptual metaphor in the sense provided in the previous subsection, a large set of figurative language expressions do not appear to relate to a system of mappings, in contrast to compound metaphors such as LOVE IS A JOURNEY (see Table 1). Such linguistic metaphors appear not to exhibit a direct grounding in experience either, in contrast to primary metaphors. A case in point concerns poetic metaphor. To make this clear, consider the following translation of the poem Free Union by the French surrealist poet André Breton:

My wife whose hair is brush fire

Whose thoughts are summer lightning

Whose waist is an hourglass

Whose waist is the waist of an otter caught in the teeth of a tiger

Whose mouth is a bright cockade with the fragrance of a star of the first magnitude

Whose teeth leave prints like the tracks of mice over snow

Whose tongue is made out of amber and polished glass

Whose tongue is like a stabbed wafer

A range of linguistic metaphors are evident in this poem, in which one entity - the poet's wife - is being understood in terms of an attribute or facet of another. For example, the poet asks one to think of his wife's waist in terms of an hourglass. ${ }^{4}$

\footnotetext{
${ }^{4}$ See the discussion of this in (Lakoff \& Turner 1989).
} 
In their 1989 book More Than Cool Reason, George Lakoff and Mark Turner attempt to apply the core insights of CMT to poetic metaphor. Yet Lakoff and Turner are, in effect, forced to concede that a significant proportion of poetic metaphor - as exemplified by the poem above - cannot be accommodated in a straightforward way by CMT. By denying a role for comparison or similarity and claiming that linguistic metaphors are motivated by asymmetric conceptual mappings deriving from embodied experience, how are metaphors of the sort exhibited in the poem to be accounted for?

The solution is something of a fudge. Lakoff and Turner concede that linguistic metaphors of the sort apparent in Free Union are not grounded in experiential correlation. They called metaphors of this sort image metaphors. An image metaphor involves understanding one entity in terms of aspects of the perceptual experience associated with another. Yet, they attempt to retain parts of the CMT account by claiming that image metaphors still involve conceptual metaphor. However, the nature of the conceptual metaphor process is a 'one shot': i.e., a single mapping involving structuring the target concept asymmetrically in terms of the source. One difficulty for such an account is that it cannot exclude a bi-directional relationship between target and source. After all, in CMT as classically formulated, the asymmetry that holds between target and source is a consequence of an apparent distinction between abstractness as in LOVE and concreteness as in JOURNEY. In what sense is a female waist any more or less abstract or concrete than an hour glass? The poet might as well have described the splendour of an hourglass and borrowed attributes of his wife to describe the hourglass.

A further problem is that, in later versions of CMT with the advent of the construct of primary metaphor - which also involves a single mapping between source and target - there is a clear experiential basis: a correlation that motivates the conceptual metaphor. Yet poetic metaphor of the type apparent in Free Union, while in some ways akin to primary metaphor (e.g., involving a single mapping between two concepts), is not plausibly motivated by recurring and ubiquitous correlations in experience. This begs the question how to account, in a principled way, for the apparent disjunction between image metaphors on one hand and primary metaphors on the other, while attempting to retain CMT - which is to say, a one-size-fits-all perspective - for the entire gamut of metaphoric phenomena.

In addition to so-called image metaphors, an additional class of linguistic metaphors pose difficulties for the CMT account. These include those linguistic metaphors associated with the predicate nominative form that have traditionally been studied in the literary and philosophy-oflanguage traditions. Examples include:

(3) a. Juliet is the sun.

b. Achilles is a lion.

c. Sam is a wolf.

d. My lawyer is a shark.

e. My job is a jail.

f. My boss is a pussycat. 
One of the clear difficulties for CMT with examples of this type - as well as the image metaphors discussed above - is maintaining that they have an experiential basis. Sometimes they may plausibly have, as in:

(4) Sally is a block of ice.

Grady (1999) suggests that an example such as this may be motivated - at least in part - by the conceptual metaphor INTIMACY IS PROXIMITY. This primary conceptual metaphor is presumably grounded in the experiential correlation that holds in human experience between intimacy and proximity.

What is less clear is how other examples that share this form might be motivated by experiential correlation. To make this clear, consider the example in (3f). A linguistic example such as this is normally interpreted to mean that the boss in question is friendly, docile - perhaps easily manipulated. For this example to have an experiential basis in the sense of CMT, the boss would need to be seen consistently with a cat. It is recurring and inevitable co-occurrence - correlation - which, one should recall, provides conceptual metaphor - held to motivate linguistic metaphor - with its experiential basis. However, one can deploy the expression in (3f) to refer to 'my boss' without having ever experienced a correlation between 'my boss' and 'pussycat'.

With characteristic insight, Joseph Grady, a former student of George Lakoff and the pioneering force behind the notion of primary metaphor, has recognized (1999) that conceptual metaphor cannot be maintained as providing an account for all types of linguistic metaphor. He observes that linguistic metaphors of the sort captured in (3) appear not to have the same basis as primary metaphors or conceptual metaphors that seem to invoke primary metaphors: namely, compound metaphors such as LOVE IS A JOURNEY. To account for this, he invokes a distinction between what he refers to as metaphors based on correlation and those based on what he terms resemblance. In so doing, Grady is saying something more in keeping with the received view so roundly criticized by Lakoff, Johnson, and Turner.

For Grady, linguistic metaphors such as those exemplified in (3) are resemblance based. That is, they invoke a level of functional resemblance. For instance, with respect to the example in (3f), a property associated with pussycats - their docility - is attributed to a particular individual labelled 'my boss'. Image metaphors might then be seen as also involving resemblance - the resemblance in question being perceptual rather than functional.

Grady effectively concedes that a - presumably large - subset of linguistic metaphors are not motivated by conceptual metaphor: those that are grounded in experience and hence correlational in nature. This conclusion is important in at least two ways. First, it asserts that the claim for conceptual metaphor as the underlying motivation for all linguistic metaphors may not, in fact, hold. There may well be a class of linguistic metaphors that are motivated - in some sense - by comparison. Second, far from undermining CMT, it demonstrates how CMT successfully identifies a type of linguistic 
metaphor that had not previously been studied in a systematic way. Metaphors of this kind - as evident, for example, in (1) - plausibly have an experiential basis.

\subsection{The distinction between conceptual and discourse metaphors}

In this section I outline some of the key differences between conceptual metaphor and resemblance or, as I prefer, discourse metaphor. I argue that resemblance metaphors are a subset of discourse metaphors.

It is often suggested in the literature that conceptual metaphors are activated automatically during language use. Lakoff and Turner (1989) claim that, when linguistic metaphors appear so hackneyed and conventional they no longer pass for metaphors at all - as in everyday expressions such as long in a long time - this demonstrates that the conceptual metaphor (in this case DURATION IS LENGTH) is alive and well. In the last decade, psycholinguistic and psychophysical behavioural evidence has begun to provide highly suggestive empirical support for this view.

The paradigm case study in the experimental psychology literature for investigating the psychological reality of conceptual metaphor is space-to-time mappings. Recent evidence has begun to suggest that aspects of time are, indeed, structured in terms of space. Important experimental support is reported in (McGlone \& Harding 1998, Boroditsky 2000, Núñez et al. 2006). ${ }^{5}$ Perhaps the most telling study to date in this area is reported in (Casasanto \& Boroditsky 2008). In their study, Casasanto and Boroditsky employed a 'growing lines' experimental paradigm in which lines 'grow' across a computer screen for different lengths and for different time periods before disappearing. Subjects were then asked to evaluate either the spatial extent or the duration of the lines. Casasanto and Boroditsky found that the subjects' evaluations of spatial extent were not influenced by duration, while evaluations of duration were influenced by spatial extent. In other words, the space-to-time mapping is asymmetric in the way predicted by CMT. Perhaps more importantly for present purposes, the conceptual metaphor is activated automatically and - in this experiment - in the absence of language. Put another way, subjects cannot help activating spatial representations when performing temporal processing. This finding appears to support the view that conceptual metaphors are automatically activated and highly entrenched in the conceptual system, as claimed by Lakoff and Johnson.

Now consider discourse metaphors. As I have already shown, a varied class of linguistic metaphors - including so-called 'image' metaphors, those associated with the predicate nominative ' $\mathrm{X}$ is a Y' form, and lexical blends (e.g., frankenfood: Zinken 2007) - appear not to be grounded in experience, in the sense claimed by CMT. These 'resemblance' metaphors I dub discourse metaphors (see e.g. Zinken 2007$)^{6}$ because the key property associated with metaphors of this kind is that they

\footnotetext{
${ }^{5}$ For a wide-ranging literature review, see (Evans 2013).

${ }^{6}$ While Zinken introduced the term 'discourse metaphor' into the literature, my use departs from Zinken's somewhat narrower definition.
} 
appear contingent on language use. They arise to facilitate communicative intentions and consequently can evolve over time, either becoming highly entrenched lexical metaphors or dropping out of use altogether. Unlike conceptual metaphors, discourse metaphors appear not to be independent of language: they arise in the context of language use. ${ }^{7}$ Also unlike conceptual metaphors, they are not stable but rather evolve, mediated by the ways and contexts in which they are deployed.

To take one example, consider the lexical metaphor frankenfood. The term was first used in the mid 1990s, particularly in Europe, propagated by NGOs such as Friends of the Earth in response to the perceived dangers of foodstuffs making use of genetically modified (GM) crops. As the perceived threat of GM foods diminished, the term became less frequent in public discourse (Zinken 2007). Zinken argues that discourse metaphors arise to fulfil a specific communicative function. When that function is no longer required, the discourse metaphor may disappear.

Another example of how discourse metaphors are influenced by use relates to the following. Discourse metaphors can become lexicalized and so re-analyzed as having a different semantic function from the one they originally arose to signal. A clear example of this is the metaphoric use of the word tart. It was originally applied in the Nineteenth Century to describe a well-dressed or attractive girl or woman and took the form of a positive evaluation. However, its narrowed application to a subset of attractive and even gaudily dressed women - namely, prostitutes - led to its developing a negative evaluative function. This semantic process has continued, such that the term tart is now applied widely to express a negative assessment of fidelity across a range of semantic fields. An attested recent example in the British national press is the expression credit card tart: a consumer who serially switches credit-card companies to gain the best interest rate or introductory interest-free offer. This example demonstrates one consequence of the use of discourse metaphors: they can take on more abstract semantic functions than those they were originally employed to express. That is, discourse metaphors, when first deployed, are somewhat novel. As they become better established, they appear to take on a more generic meaning, which corresponds to them becoming more entrenched. Based on this observation, Glucksberg has argued (2001, Glucksberg \& Keysar 1990) that what I refer to as discourse metaphors behave like lexicalized categories. A tart is a paradigm example of such a category: a person whose fidelity is unreliable in any sphere.

Bowdle and Gentner (2005) have put forward a hypothesis - the Career of Metaphor Hypothesis - that captures the observed trajectory for what I refer to as discourse metaphors. They propose that discourse metaphors exhibit a cline in terms of conventionality, following an evolutionary career that reflects their usage. When a new discourse metaphor first emerges, it is highly novel. Following Gentner's Structure Mapping hypothesis (Gentner 1983, Gentner et al. 2001), Bowdle and Gentner propose that discourse metaphors are motivated by establishing an analogical relationship between one idea and another. In other words, discourse metaphors facilitate projection of a system of relations

\footnotetext{
${ }^{7}$ I am not claiming that discourse metaphors do not rely on conceptual processes for their formation. I am simply claiming that language appears essential to their formation and propagation: a situation that is not the case with conceptual metaphors.
} 
from one domain onto another, regardless of whether the source and target domains are intrinsically similar. The Career of Metaphor Hypothesis contends that, over time, the inferences associated with analogical mapping becomes entrenched such that the discourse metaphor becomes lexicalized. One consequence is that, at the conceptual level, the structure-mapping operation closes down - in contrast to conceptual metaphor, where it remains active in the conceptual system. Another is that the lexicalized discourse metaphor takes on more abstract properties, serving as a reference point for a particular category of things.

To illustrate, take the word roadblock considered by Bowdle and Gentner (2005: 198). 'There was presumably a time when this word referred only to a barricade set up in the road. With repeated use as the base term of metaphors such as Fear is a roadblock to success, however, roadblock has also come to refer to any obstacle to meeting a goal.'

The Career of Metaphor Hypothesis has empirical support. A robust finding in metaphor comprehension studies (e.g., Blank 1988, Coulson 2008, Giora 2008) is that conventional metaphors are understood more quickly than novel ones. This is only to be expected if the Career of Metaphor Hypothesis is correct. After all, once discourse metaphors have become lexicalized, they are entrenched as part of the linguistic system; this should lead to faster retrieval.

In sum, I suggest that there are good reasons for distinguishing between two quite distinct types of metaphor. Conceptual metaphors are mappings that inhere in the conceptual rather than the linguistic system. They are relatively stable in long-term memory and are invariably activated during symbolic processing, whether due to linguistic or non-linguistic processing. In contrast, discourse metaphors arise in language use, to facilitate a linguistically mediated communicative intention. They are made possible, initially, by generalized analogical processing at the conceptual level. The inferences that arise from this process become lexicalized as part of the lexical concept associated with the discourse metaphor form and so become detached from the conceptual system. This process of reanalysis results in a discourse metaphor that is more schematic and abstract in nature: one that can refer to abstract properties found in the original motivating communicative context but which applies to a wider range of contexts. In other words, discourse metaphors evolve from novel analogies to lexicalized units that embody an abstract category.

\section{DISSOCIATION BETWEEN LANGUAGE AND CONCEPTUAL METAPHORS}

One of the assumptions that conceptual metaphor researchers often appear to make is that conceptual metaphors directly motivate patterns in language usage. In this section, I examine and nuance this claim. While conceptual metaphors are clearly important in language processing - as empirically verified by a range of behavioural studies (e.g., Boroditsky 2000, McGlone \& Harding 1998, Gentner et al. 2002) - they are not the whole story. As I argue below, it is difficult to maintain that conceptual metaphors are solely responsible for figurative language. More specifically, I show that conceptual metaphors do not motivate figurative language in a direct way. While conceptual metaphors do have a 
constraining influence on linguistic expressions, language represents a semiotic system that is, in principle, distinct from the conceptual system: the venue for conceptual metaphors. The linguistic system is subject to language-internal pressures giving rise to semantic units that are, in principle, independent from conceptual metaphors (Evans 2009b). This level of cognitive representation is what I refer to as the lexical concept (2006, 2009a, 2009b, 2013). While conceptual metaphors may have a constraining influence on the nature of lexical concepts, nevertheless, lexical concepts operate independently of conceptual metaphors. Usage patterns in language are not predictable on the basis of conceptual metaphors alone, but arise on the basis of lexical concepts in the linguistic system and conceptual metaphors - and, indeed, other types of representation in the conceptual system.

\subsection{Evidence for a dissociation between conceptual metaphors and lexical concepts}

There are good grounds for thinking that conceptual metaphors, while part of the story, underdetermine the linguistic metaphors that show up in language use. Consider the conceptual metaphor STATES ARE LOCATIONS. It has been claimed in the CMT literature that this metaphor motivates examples of the following kind:

(5) We are in love/shock/pain ( $c f$. we are in a room).

(6) We are at war / variance / one / dagger's drawn / loggerheads: 'state' sense ( $c f$. we are at the bus stop: 'spatial' sense).

(7) We are on red alert / (our) best behaviour / the look-out / the run: 'state' sense ( $c f$. we are on the bus: 'spatial' sense).

While the English prepositions in, at, and on relate canonically to spatial relations of particular kinds, it is due to conceptual metaphor - so Lakoff and Johnson (e.g., 1999) claim - that they can refer to abstract states such as love, war, red alert, and so forth. However, conceptual metaphor does not predict why there are different patterns in the sorts of states that can be encoded by different prepositions in English. After all, the semantic arguments that ordinarily co-occur with in, at, and on are constrained. While one can be in love, shock, pain, or trouble, the semantic arguments that collocate with at and on are unacceptable applied to in, as demonstrated below (signalled by an asterisk):

(8) *We are in war / variance/ one / dagger's drawn / loggerheads: 'state' sense.

(9) *We are in red alert / (our) best behaviour / the look-out / the run.

Similarly, the semantic arguments that collocate with in and on do not collocate with at, and so on. Closer examination of the linguistic facts suggests that the way in which semantic arguments collocate is preposition-specific (= form-specific). Take in and on by way of illustration: 
(10) a. John is in trouble/danger.

b. Jane is in love/awe.

c. Fred is in shock.

d. Jake is in a critical condition.

(11) a. The guard is on duty.

b. The blouse is on sale.

c. The security forces are on red alert.

While both in and on encode abstract states, the kinds of states they encode appear to be of quite different kinds, as evidenced by the range of object arguments they take. The semantic arguments that on selects for relate to states that normally hold for a limited period of time and that contrast with salient states in which the reverse holds. For instance, being on duty contrasts with being off duty: the normal state of affairs. Likewise, being on sale is temporally limited. Sales occur for limited periods at specific times during the year: e.g., a winter sale. Being on red alert contrasts with the normal state of affairs, in which a lesser security status holds. For all of these, the states in question can be construed as volitional: i.e., to be on duty / sale / red alert requires a volitional agent who decides that a particular state will hold and takes the requisite steps to bring such a state of affairs about.

In contrast, the semantic arguments selected for by in relate to states that do not necessarily hold for a limited period of time and do not contrast in any obvious way with a 'normal' state of affairs. While states encoded by on are - in some sense - volitional, states associated with in are - again, in some sense - non-volitional. One does not usually choose to be in love, in shock, or in a critical condition; nor can one normally, by conscious act of will, bring such states about. These states are ones people are affected, constrained, and influenced by, rather than ones that are actively - in the sense of consciously - chosen.

Detailed linguistic analysis reveals that the range of states encoded by in and on exhibit even more-fine-grained distinctions, which nevertheless adhere to the general preposition-specific generalization I just outlined. Consider in first:

(12) a. The cow is in milk.

b. The girl is in love.

c. John is in trouble/debt.

d. He's in banking [i.e., works in the banking industry].

While each of these examples relates to a 'state' of some kind, each relates to a slightly different sort of state: that which has a physical cause (12a) - the state of being 'in milk', a consequence of the physical production of milk; that which has a psychological or emotional cause $(12 b)-$ the consequence of a subjective state that may or may not have physical (i.e., observable) manifestations; that which has a social/inter-personal cause (12c) - the result of social/interpersonal interactions that 
result in an externally maintained state; and, finally, that which results from a habitual professional activity (12d). Each of these states takes distinct semantic arguments, relating a particular entity to quite different sorts of states. In appears to select for semantic arguments that relate to a delimited set of state types that can be categorized as follows:

Physiological state, resulting in a 'product'.

(13) a. The cow is in milk.

b. The cow is in calf.

c. The woman is in labour.

Psychosomatic state: i.e., subjective/internal state.

(14) a. John is in shock/pain (over the break-up of the relationship).

b. John is in love (with himself/the girl).

Socio-interpersonal state: i.e., externally maintained state.

(15) a. The girl is in trouble (with the authorities).

b. John is in debt (to the tune of $£ 1000 /$ to the authorities).

Professional state: i.e., professional activity habitually engaged in.

(16) a. He is in banking.

b. She is in insurance.

Now consider on. The semantic arguments selected for by on appear to relate to adjectives or nouns of action involving a particular state that can be construed as 'active' or 'functional', in contrast to a (perhaps) normative scenario in which the state does not hold. In other words, states described by on are often temporally circumscribed: they endure for a prescribed or limited period of time. In this way, the states referred to are quite distinct from those that in describes: the notion of being non-volitionally affected - apparent with in - is almost entirely absent. Consider some examples:

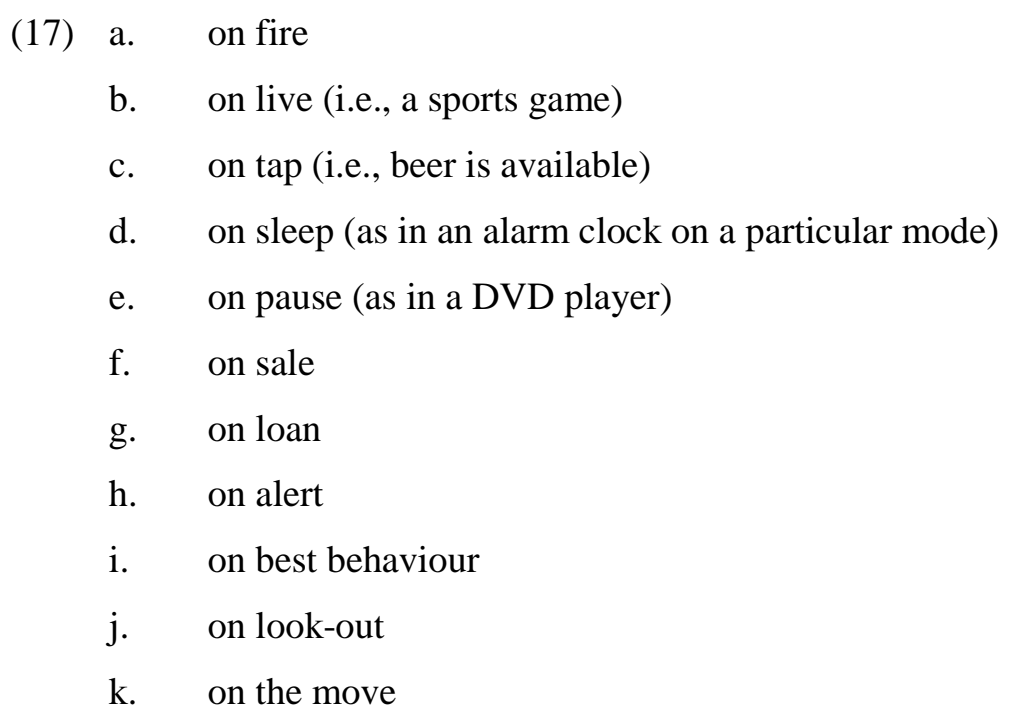


1. on the wane
m. on the run

What does this reveal about the existence of conceptual metaphors? The distinct collocational patterning associated with the state meanings of English prepositions like in and on is not predicted by positing a general STATES ARE LOCATIONS conceptual metaphor. This does not necessarily mean that one does not exist. ${ }^{8}$ What it does reveal is that the kind of states encoded by particular forms pattern in ways not predicted by - and, in principle, independent of - a more abstract level of conceptual metaphor.

Empirical findings such as these have led me to posit a dissociation between conceptual metaphor and the level of cognitive representation I refer to (e.g., 2004, 2009b, 2010a, 2010b, 2013) as that of lexical concepts. While a conceptual metaphor provides a level of non-linguistic - which is to say, conceptual - organization instantiated in long-term memory, which presumably constrains the nature and range of lexical concepts, a lexical concept is a unit of purely linguistic semantic knowledge. ${ }^{9}$ Lexical concepts are conventionally paired with forms. Among other things, they specify the range of semantic arguments that a lexical form can pair with. In (2010a) I argue that, while in has conventionally paired with it the distinct lexical concepts [PHYSIOLOGICAL STATE], [PSYCHO-SOMATIC STATE], [SOCIO-INTERPERSONAL STATE], and [PROFESSIONAL STATE], corresponding to the examples in (13), (14), (15), and (16), the preposition on has paired with it the lexical concept [ACTIVE STATE].

[ACTIVE STATE] versus [PHYSIOLOGICAL STATE], [PSYCHO-SOMATIC STATE], [SOCIOINTERPERSONAL STATE], and [PROFESSIONAL STATE] reflect a distinction in the types of states conventionally associated with each preposition. In sum, the way English language users differentially deploy in and on suggests that, in addition to a putative STATES ARE LOCATION conceptual metaphor, they use more specific lexical concepts, which are specific to each form.

\subsection{Language change}

In the CMT literature, it has sometimes been claimed (e.g., Heine et al. 1991; Lakoff \& Johnson 1999; Sweetser 1988, 1990) that conceptual metaphors directly motivate language change. In this section, I briefly address this issue. As in the previous section, I conclude that, while conceptual metaphors may have a role in constraining the directionality of language change, the linguistic facts are better accounted for by assuming that language change is effected at the linguistic level - operating at, and

\footnotetext{
${ }^{8}$ As lexical concepts are language specific, my claim is that cognate forms for in, on, and at may not provide the same range of lexical concepts. Indeed, there are multiple languages where the ideas conveyed in (17), using on, would have to be rendered in quite different ways.

${ }^{9}$ A lexical concept - a central idea in LCCM theory (Evans 2009b, 2013) - is a cognitive representation that forms part of the linguistic rather than the conceptual system. While a lexical concept is a concept qua unit of knowledge, it is relatively impoverished; it does not, of itself, facilitate rehearsals of non-linguistic information such as perceptual knowledge: i.e., simulations. To claim that a lexical concept does not inhere in the conceptual system does not entail that it is not a mental representation (for full details, see Evans 2009b).
} 
on, lexical concepts and driven by usage. First, I consider the type of grammatical change known as grammaticalization. I then examine semantic change leading to the rise of polysemy.

Grammaticalization is the phenomenon whereby a linguistic expression undergoes form-function re-analysis such that a lexical item shifts from the open-class to the closed-class system (e.g., Bybee et al. 1994, Heine et al. 1991, Heine \& Kuteva 2007). It also applies to linguistic units that have already undergone grammaticalization, resulting in more grammaticalized units. To demonstrate that grammaticalization is motivated by conceptual metaphor, evidence is required of a shift in an expression's function from a more concrete to a more abstract domain. An example would be a shift from SPACE to TIME, motivated by one or more of the space-to-time conceptual metaphors that have been posited in the literature (e.g., Lakoff \& Johnson 1999, Moore 2006).

Because conceptual metaphors involve two domains - a source and a target - a CMT account of grammaticalization predicts that form-function re-analysis holds at the level of domains. If conceptual metaphor directly motivated language change, one would expect to see grammaticalized linguistic units that exhibit either a meaning relating to a concrete domain or one that corresponds to the more abstract target domain. In other words, the prediction is that conceptual metaphors motivate language change such that there is a discrete shift from one domain to another. Examples that fall somewhere between source and target domains might be seen as counterevidence for the metaphorical extension account.

For example, it has been claimed that the conceptual metaphor TIME IS OBJECTS IN MOTION (ALONG A PATH) has led to the grammaticalization of the construction (be) going to. At one point in the history of the language, this construction related only to an ALLATIVE (i.e., motion) meaning. The conceptual metaphor extension account holds that the concrete ALLATIVE meaning has evolved a more abstract - and hence more grammaticalized - FUTURE meaning (Heine et al. 1991, Sweetser 1988). These meanings are illustrated below:
(18) a. John is going to town.
[ALLATIVE]
b. It is going to rain.
[FUTURE]

However, the be going to construction exhibits senses that are intermediate between those exhibited in (18). Consider the following:

(19) a. I'm going to eat.

b. John is going to do his best to make Mary happy.

While be going to in (18a) has a purely ALLATIVE meaning and be going to in (18b) a purely FUTURE meaning, (19a) has a meaning of INTENTION. It is possible to view this sense as having a remnant of the spatial (ALLATIVE) meaning: the speaker must move to an appropriate location to facilitate the act of eating. This contrasts with (19b), which encodes INTENTION and PREDICTION, has but no spatial (ALLATIVE) sense. Examples like (19a) and (19b) are potentially problematic for a conceptual 
metaphor account, showing that grammaticalization involves a continuum of meanings, not a clear-cut semantic shift from one domain (SPACE) to another (TIME).

If grammaticalization is not directly motivated by conceptual metaphor, what gives rise to the apparent semantic shifts? An increasing number of scholars propose that language use provides the motivating context for language change: e.g. (Evans \& Enfield 2000, Traugott \& Dasher 2004). The nuances in meaning apparent in examples such as (19) are better accounted for by assuming that contextualized inferences - which Traugott and Dasher call invited inferences - emerging in specific contexts of use where two or more meanings are apparent - what Evans and Enfield refer to as bridging contexts - give rise to form-function re-analysis: i.e., a form comes to be associated with a new meaning. Through recurrence of invited inference in similar bridging contexts, the situated inference is re-analysed and, through a process of de-contextualization, gives rise to an entrenched semantic unit: a new lexical concept. This account, which views language-in-use rather than conceptual metaphor as the engine of change, better accords with the observable facts.

Now consider the issue of semantic change itself: semantic change results in a new sense unit coming to be associated with a lexical form. This results in the phenomenon known as polysemy, where a single form is conventionally associated with two or more related sense units. In his classic work on the preposition over, Lakoff (1987) reserves a central role for conceptual metaphor in the rise of polysemy. More recently, Tyler and I (Tyler \& Evans 2001, 2003) have argued that the semantic networks associated with word forms, of which over is a paradigm example, are better accounted for in terms of sense extension via the usage-based explanation described above - giving rise to new lexical concepts. That is, semantic change and the emergence of polysemy are consequences of changes in the linguistic system rather than being directly motivated in the top-down way offered by CMT, according to which conceptual metaphors direct semantic change.

Consider the following examples, which are representative of what Tyler and I describe as an [ABOVE] and a [COVERING] lexical concept respectively:

(20) a. The lamp is over the table.

b. The clouds are over the sun.

In (20a), the natural reading involves a spatio-geometric configuration such that the lamp is higher than, and in a region that at least partially overlaps with the vertical axis of, the table. In (20b), no such spatio-geometric relationship holds. At least from an earth-bound perspective, the clouds are lower than the sun. The reading conventionally associated with (20b) concerns a covering relationship: the sun is covered - occluded from view - by the clouds. The appropriate reading 'above' versus 'covering' - appears to be, at least in part, a function of the word over, which in these examples has two distinct meaning units conventionally associated with it.

Diachronically, the [ABOVE] lexical concept precedes the [COVERING] one. Indeed, the [ABOVE] lexical concept appears to be among the earliest - if not the earliest - lexical concept associated with 
over in the history of the language (Tyler \& Evans 2003). Given that semantic change is a motivated process, it stands to reason that [COVERING] emerged from [ABOVE] - or from a lexical concept itself derived ultimately from [ABOVE].

Tyler and I have argued that the most plausible motivation for the emergence of the [COVERING] lexical concept derives from usage contexts in which an [ABOVE] meaning implies a covering interpretation. That is, we propose that semantic change, resulting in the emergence of polysemy, involves a bridging context. Consider the following example:

The tablecloth is over the table.

This sentence describes a spatial scene in which one entity - the one above - is larger than the landmark entity, located below. Because the tablecloth is larger, and located higher, than the table, the tablecloth covers and so occludes the table from view. In other words, covering is a situated inference: it emerges in this context as a function of the spatio-geometric relation between the table and the tablecloth. The use of over, in contexts such as these, leads to this situated implicature becoming detached from its context of use and re-analysed as a lexical concept in its own right. Following pioneering work on semantic change by Elizabeth Closs-Traugott (e.g., Traugott 1989), Tyler and I refer to this process of detachment and re-analysis as pragmatic strengthening. The rampant polysemy exhibited by words is primarily a function of changes to the linguistic system, resulting in the emergence of new lexical concepts - driven by usage rather than by conceptual metaphor.

\section{THE NATURE OF FIGURATIVE MEANING CONSTRUCTION}

Of course, knowing that conceptual metaphors have psychological reality does not, in and of itself, facilitate an account of figurative meaning construction. For one thing, conceptual metaphors are relatively stable knowledge structures, while meaning is a flexible, open-ended, and dynamic process. For another, as I have previously argued, conceptual metaphors cannot account for more than a subset of the figurative language that arises in ordinary language use.

Recently, Fauconnier and Turner have developed a theory of Conceptual Blending (BT), which provides a programmatic account of the sorts of conceptual processes likely to be implicated in the process of (figurative) meaning construction. While integration - or blending - appears to be fundamental to meaning construction, conceptual integration is likely to take many different forms (Evans 2010b). Moreover, any account must grapple with the role of language as it interfaces with non-linguistic knowledge structures. Careful dissection is required of the nature of linguistic and nonlinguistic representations and how they interface (Evans 2009b, 2010b). This work has yet to be done in any detail.

Nevertheless, it is becoming clear what the desiderata are for a generalized theory of conceptual integration. First, one requires an account of the roles of linguistic and non-linguistic knowledge in 
meaning construction. This includes discourse metaphors and lexical concepts, which lie at the linguistic end of the knowledge continuum, as well as conceptual metaphors and other conceptual knowledge representation, which reside in the conceptual system. Second, one requires a means of modelling the compositional and inferential processes that facilitate integration.

Recently, I have begun to develop an account of linguistically mediated meaning construction:the Theory of Lexical Concepts and Cognitive Models, or LCCM theory for short. This accords with the agenda developed by Fauconnier and Turner (2002) for BT. One of the aims of LCCM theory is to provide a detailed account of the principles that guide composition: among the fundamental aspects of conceptual integration. It attempts to provide a principled account of the integration of linguistic content (semantic structure) and conceptual content (conceptual structure): one of the key issues in meaning construction. I briefly introduce the LCCM approach to figurative language before discussing how it allows one to model the way language facilitates the activation of conceptual metaphors and other non-linguistic knowledge structures in the construction of figurative meaning.

\subsection{LCCM theory: An overview}

LCCM theory (Evans 2006, 2007, 2009a, 2009b, 2010a, 2010b, 2013) accounts for lexical representation and semantic composition in language understanding. It models the nature of symbolic units in language: in particular, semantic structure; the nature of conceptual representations; and the compositional mechanisms that give rise to the interaction between these two sets of representations the semantic and the conceptual - in service of linguistically mediated meaning construction. LCCM theory derives its name from two theoretical constructs that are central to the model developed: the lexical concept and cognitive model.

LCCM theory's overarching assumption is that the linguistic system emerged, in evolutionary terms, much later than the conceptual system. On this account, the utility of a linguistic system is that it provides an executive control mechanism to facilitate the deployment of conceptual representations in service of linguistically mediated meaning construction. Hence, 'semantic' representations in the two systems are qualitatively distinct. I model semantic structure - the primary semantic substrate of the linguistic system - in terms of the theoretical construct of the lexical concept (see Evans 2009b for details). A lexical concept is a component of linguistic knowledge - the semantic pole of a symbolic unit, in Langacker's (e.g., 1987) terms - encoding a bundle of various types of highly schematic linguistic content (see Evans 2006, 2009a, 2009b, 2013).

While lexical concepts encode highly schematic linguistic content, a subset - associated with open-class forms - are connected, and hence facilitate access to the conceptual system. Lexical concepts of this type are open-class lexical concepts. ${ }^{10}$ Such lexical concepts are typically associated with multiple association areas in the conceptual system, collectively referred to as its access site.

\footnotetext{
$\overline{{ }^{10} \text { See Evans (2009b) for my rationale. }}$
} 
The linguistic system evolved to harness the representational power of the conceptual system for purposes of communication. The human conceptual system - at least in outline - is not far removed from that of other primates (Barsalou 2005) and shows similarities with yet more species (Hurford 2007). In contrast to the linguistic system, the conceptual system evolved to facilitate functions such as perception, categorization, inference, choice, and action, rather than communication. In LCCM theory, conceptual structure - the semantic representational substrate of the conceptual system - is modelled by the theoretical construct of the cognitive model. A cognitive model is a coherent body of multimodal knowledge grounded in the brain's modal systems. It derives from the full range of experience types processed by the brain including sensorimotor experience, proprioception, and subjective experience, including affect.

The conceptual content encoded as cognitive models can be re-activated during a process known as simulation: a general-purpose computation performed by the cognitive system to implement the range of activities subserving a fully functional conceptual system. Such activities include conceptualization, inferencing, choice, categorization, and the formation of ad hoc categories. ${ }^{11}$

In line with recent evidence in the cognitive science literature, LCCM theory assumes that language facilitates access to conceptual representations in order to prompt for simulations (Glenberg \& Kaschak 2002, Kaschak \& Glenberg 2000, Pulvermüller 2003, Vigliocco et al. 2009, Zwaan 2004; for a review, see Taylor \& Zwaan 2009, Shapiro 2010; for nuanced views on the role of simulations, see Chatterjee 2010, Mandler 2010).

An important construct in LCCM theory - essential to an account of figurative language understanding, as I shall show below - is that of the cognitive model profile. Because an open-class lexical concept facilitates access to numerous association areas within the conceptual system, it facilitates access to numerous cognitive models, themselves connected to other cognitive models. The range of cognitive models to which a lexical concept facilitates direct or indirect access is its cognitive model profile.

Consider the cognitive model profile for the lexical concept I gloss as [FRANCE], associated with the form France. A partial cognitive model profile for [FRANCE] is represented in Figure 1.

Figure 1 attempts to capture the sort of knowledge language users must have access to when speaking and thinking about France. As it shows, the lexical concept [FRANCE] provides access to a potentially large number of cognitive models, each of which consists of a complex, structured body of knowledge that provides access to other sorts of knowledge. LCCM theory distinguishes cognitive models that are directly accessed via the lexical concept: primary cognitive models; from those cognitive models that form sub-structures of those directly accessed: secondary cognitive models. These secondary cognitive models are indirectly accessed via the lexical concept.

\footnotetext{
${ }^{11}$ For discussion and findings relating to the multimodal nature of conceptual representations and the role of simulation in drawing on such representations in facilitating conceptual function see, for instance, Barsalou (1999, 2008), Glenberg (1997), Gallese and Lakoff (2005), and references therein.
} 


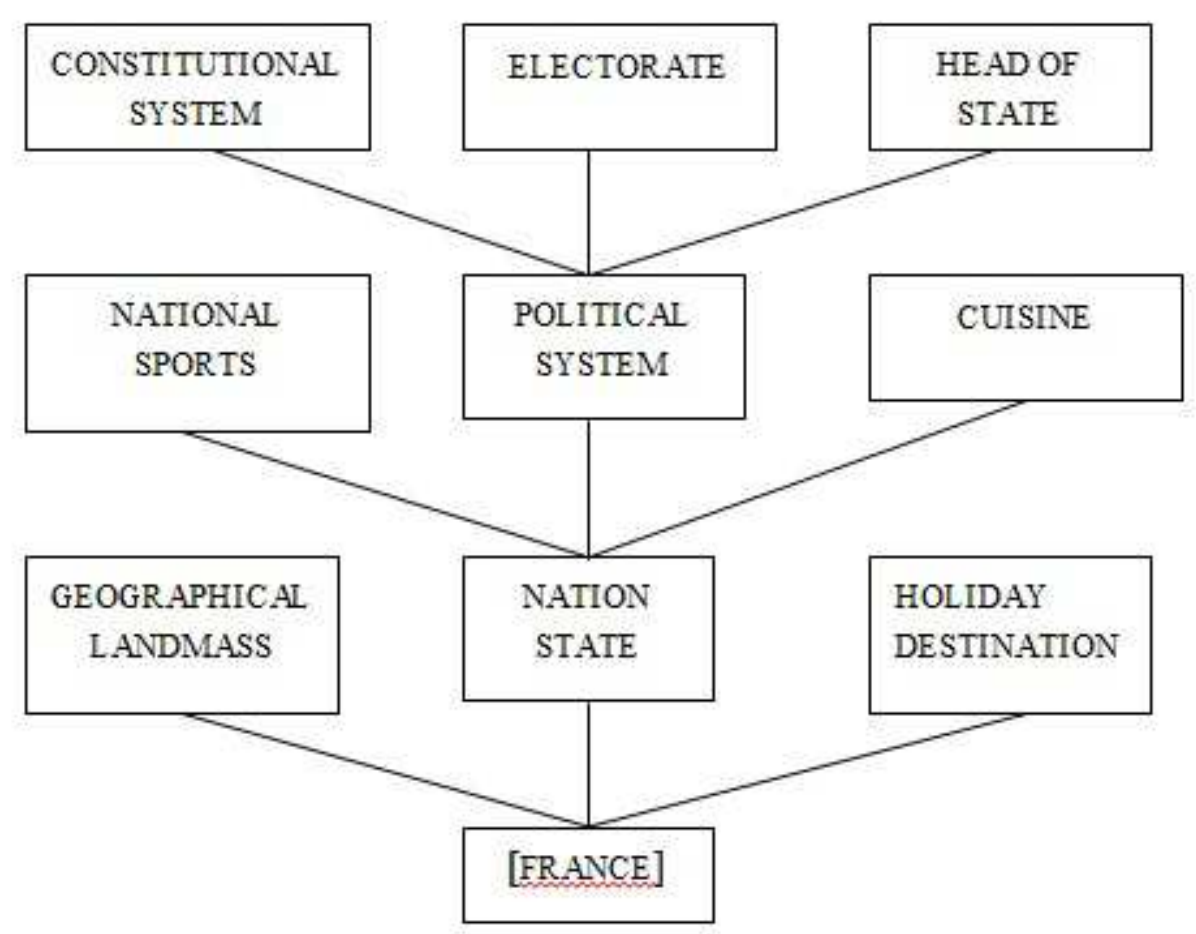

Figure 1: Partial cognitive model profile for [FRANCE].

The lexical concept [FRANCE] affords access to a number of primary cognitive models, which make up the primary cognitive model profile for [FRANCE]. These are hypothesized to include GEOGRAPHICAL LANDMASS, NATION STATE, and HOLIDAY DESTINATION. Each provides access to further cognitive models. Figure 1 gives a flavour of this by means of the secondary cognitive models accessed via NATION STATE: the secondary cognitive model profile. These include NATIONAL SPORTS, POLITICAL SYSTEM, and CUISINE, which are hypothesized to be further removed conceptually from the lexical concept [FRANCE]. For instance, one may know that, in France, the French engage in national sports of various types - football, rugby, athletics, and so forth - rather than others; the French do not typically engage in American football, ice hockey, cricket, and so forth. One may further know that, as a sporting nation, France takes part in international sports competitions including the FIFA football World Cup, the Six Nations rugby competition, the rugby World Cup, and the Olympics. One may have access to a large body of knowledge concerning the sorts of sports French people engage in. One may have knowledge of the funding structures and socioeconomic conditions and constraints that apply to these sports in France, France's international standing in these sports, and further knowledge about the sports themselves including their governing rules. This knowledge derives from a large number of sources, including direct experience and cultural transmission - including language.

Figure 1 gives a sample of further secondary cognitive models accessed via POLITICAL SYSTEM. Each secondary cognitive model has further cognitive models to which it provides access: (FRENCH) ELECTORATE is accessed via the cognitive model (FRENCH) POLITICAL SYSTEM, which is accessed via 
the cognitive model NATION STATE. NATION STATE is a primary cognitive model; ELECTORATE and POLITICAL SYSTEM are secondary cognitive models. ${ }^{12}$

LCCM theory is motivated in large part by the observation that word meanings vary across contexts of use in terms of the conceptualization(s) that they in part give rise to. Consider the following examples relating to the lexical form France:

(22) a. France is a country of outstanding natural beauty.

b. France is one of the leading nations in the European Union.

In (22a), France relates to a geographical landmass coincident with the borders of mainland France. In (22b), France relates to a political nation state, encompassing its political infrastructure. The essential insight of LCCM theory is that linguistic - and, indeed, extra-linguistic - context guides the way the lexical concept [FRANCE] activates the relevant cognitive model in the cognitive model profile to which [FRANCE] facilitates access. While the details of how this is achieved are beyond the scope of this paper (see Evans 2009 b for details), the idea is as follows. In (22a) the linguistic context activates the LANDMASS cognitive model accessed via [FRANCE]. In (22b), the linguistic context activates the NATION STATE cognitive model accessed via [FRANCE]. Context constrains which part of the cognitive model profile a given lexical concept facilitates access to. This allows one to model the protean nature of word meaning.

\subsection{Literal versus figurative conceptions ${ }^{13}$}

As I have just shown, the way open-class words such as France derive their interpretation involves activation of a particular component - a cognitive model - in a given cognitive model profile. For activation to occur, the cognitive model profile accessed via the open-class lexical concepts in an expression must undergo a process LCCM theory refers to as matching. According to LCCM theory, a failure to match across two or more primary cognitive model profiles is one of the hallmarks of figurative language.

The distinction between what I refer to as a literal conception - the meaning associated with a literal utterance - and a figurative conception - the meaning associated with a figurative utterance relates to that part of a word's semantic potential - which, according to LCCM theory, relates to its cognitive model profile ( $c f$. Allwood 2003) activated in the process of constructing a conception. A literal conception canonically results in an interpretation that activates a cognitive model or models within the primary - which is to say default - cognitive model profile. A figurative conception occurs

\footnotetext{
12 The hierarchical organization of cognitive model profiles results from the empirical finding that knowledge is organized, and certain knowledge types appear to exhibit typicality effects: some types of knowledge appear to be more central and others more peripheral to particular lexical concepts. See (Evans 2009b) for discussion.

${ }^{13}$ I make no distinction here between types of figurative conception: e.g., metaphor versus metonymy; these lie beyond the scope of the present paper. For such a distinction, see (Evans 2010b).
} 
when a clash arises in the primary cognitive model profiles subject to matching. This is resolved when one of the cognitive model profiles achieves a match in its secondary cognitive model profile.

Consider the following examples, again relating to the lexical concept [FRANCE]:

Literal conception

(23) France has a beautiful landscape.

Figurative conception

(24) France rejected the EU constitution.

In (23), a literal conception arises by virtue of a match between the interpretation of the expression beautiful landscape - the result of a prior match between [BEAUTIFUL] and [LANDSCAPE] - and the primary cognitive model profile to which [FRANCE] affords access, these being the only expressions that facilitate access to cognitive model profiles. That is to say, the resulting interpretation of [BEAUTIFUL] and [LANDSCAPE] undergoes matching with the cognitive model profile to which the lexical concept [FRANCE] affords access: a search takes place in the primary cognitive model profile associated with [FRANCE]. Constrained by principles that ensure conceptual and schematic coherence (Evans 2009b), a match is achieved in the primary cognitive model profile of [FRANCE].

In (23), the GEOGRAPHICAL LANDMASS cognitive model for [FRANCE] is activated - recall the cognitive model profile for [FRANCE] presented in Figure 1. It is this cognitive model that matches the interpretation associated with the expression beautiful landscape. The conception that arises for (23) is literal, because activation occurs solely in the primary cognitive model profile of [FRANCE].

In contrast, (24) would usually be judged to be figurative in nature. France in (23) refers to a specific geographical region: that identified by the term France. France in (24) refers to the electoral majority who voted against implementing the EU constitution in a 2005 referendum. This figurative conception arises due to a clash between the primary cognitive model profile of [FRANCE] and the interpretation associated with the expression rejected the EU constitution. None of the primary cognitive models to which [FRANCE] facilitates access can be matched with that interpretation.

The failure of matching in the primary cognitive model profile requires establishing a wider search domain: namely, matching in the secondary cognitive model with cognitive models to which the lexical concept [FRANCE] provides only indirect access. This enables resolution by facilitating a search region beyond the default one: which is to say, the primary cognitive model profile.

In (24), a secondary cognitive model is identified that achieves conceptual coherence, thereby resolving the clash and achieving a match. The cognitive model that achieves activation is the ELECTORATE one (see Figure 1). The matching process results in a figurative interpretation for [FRANCE], which is that of 'electoral majority'. Because the ELECTORATE cognitive model is a secondary cognitive model, this means that the conception is figurative.

The defining feature of a literal conception is that matching occurs in the primary cognitive model profiles of the relevant lexical concepts. The defining feature of a figurative conception is a 
clash in those primary cognitive model profiles, necessitating resolution and, hence, activation of cognitive models in the secondary cognitive model profile of one or more of the relevant lexical concepts; for full details, see (Evans 2010b).

\subsection{Conceptual metaphors versus semantic affordances}

LCCM theory assumes that figurative meaning construction involves a number of different knowledge types. One knowledge type involves primary conceptual metaphors (Grady 1997b, Lakoff \& Johnson 1999). Recall that these are hypothesized to be cross-domain conceptual primitives that arise automatically on the basis of pre-conceptual, universally shared experience types. A second knowledge type involves compound metaphors (Grady 1997b, 2005; Lakoff \& Johnson 1999 prefer the term complex metaphor). These are complex bodies of knowledge arising through processes of conceptual integration, in the sense of Fauconnier and Turner: i.e., they are a type of (often very complex) blend. Specific proposals as to how they arise can be found in (Grady 1997b, 2005; Fauconnier \& Turner 2008).

The common denominator of primary and compound metaphors is that they involve knowledge recruited from other regions of conceptual space: which is to say, from other domains of experience. LCCM theory assumes that primary and compound metaphors structure the cognitive models that make up a lexical concept's cognitive model profile, as I shall show below. On the present account, conceptual metaphors - whether primary or compound - form part of the knowledge to which an open-class lexical concept facilitates access and, hence, part of the conventional body of knowledge potentially invoked by any given lexical item during the process of figurative language understanding.

In addition to knowledge of this type, lexical concepts facilitate what I refer to as semantic affordances: those knowledge types that are immanent in the cognitive model profile prior to additional structuring via conceptual metaphor. For instance, the lexical concept associated with the form whizz provides a number of possible interpretations that arise purely on the basis of the cognitive models to which it facilitates direct (primary cognitive models) and indirect access (secondary cognitive models); these inferences constitute semantic affordances. Semantic affordances are activated during the process of (figurative) language understanding, as mediated by context. Semantic affordances potentially activated by selection of the lexical concept [WHIZZ] include 'rapid motion', 'a distinct audible sound', 'lack of perceptual detail associated with the object of motion', and 'limited durational elapse to observe object of motion', as well as many others. I argue below that semantic affordances - as well as relational structure recruited via conceptual metaphor - is important in giving rise to the interpretation associated with any given open-class lexical concept during figurative language understanding.

I make four claims as to the roles of conceptual metaphors and semantic affordances in figurative meaning construction. 
Claim 1: as argued in Section 3.1, there are compelling reasons for thinking that conceptual metaphors, while part of the story, underdetermine figurative language as it shows up in language use. For instance, the conceptual metaphor STATES ARE LOCATIONS does not predict why there are different patterns in the sorts of states that can be encoded by different prepositions in English:

(25) a. She is in love ( $c f . *$ she is on love).

b. The soldiers are on red alert ( $c f . *$ the soldiers are in red alert).

Claim 2: a semantic affordance is an inference specific to a given lexical concept. It arises during figurative - and, indeed, non-figurative - language understanding due to activation of (part of) a cognitive model to which the lexical concept facilitates access: in other words, semantic affordances reside in the conceptual system and, hence, are non-linguistic in nature, although they are activated by linguistic (as well as non-linguistic) context. In principle, a lexical concept can facilitate activation of a vast number of semantic affordances, constrained only by the cognitive model profile to which it facilitates access. Moreover, a lexical concept can, in any utterance, give rise to more than one semantic affordance: a consequence of the extra-linguistic context - venue, time, interlocutors, and so forth - linguistic context, and processes of meaning construction that apply. Consider the following utterances:

(26) a. Christmas is approaching.

b. Christmas whizzed by (this year).

CMT claims (e.g., Lakoff \& Johnson 1999, Moore 2006) that the ego-centred conceptual metaphors for Moving Time allow one to understand (the passage of) time in terms of the motion of objects thorough space, thereby licensing these examples.

While examples such as these are, no doubt, in part a consequence of conceptual metaphors for time (here, in terms of their 'location' in time: either future (26a) or past (26b)), the forms approaching and whizz give rise to distinct semantic affordances that cannot be predicted solely on the basis of the common conceptual metaphor meant in CMT to license them. The semantic affordance associated with the lexical concept [APPROACHING] relates to 'relative imminence'. The event in question - in (26a), Christmas - is construed as imminent. The semantic affordance associated with [WHIZZ] in (26b) does not concern imminence, but the observer's compressed experience of the event (again, Christmas): i.e., the semantic affordance relates to the phenomenological experience that, in (26b), Christmas felt as if it lasted lesser time than is normally the case. Even while the Moving Time conceptual metaphor allows the language user to apply relational structure from her experience of objects moving in space and so interpret Christmas metaphorically as an object, part of her interpretation involves semantic affordances unique to the relevant lexical concepts for motion. Because the aforementioned inferences are specific to lexical forms, it is theoretically more accurate to assume that this aspect of meaning construction involves a bottom-up process whereby the inferences 
arise due to activation of knowledge - semantic affordances - specific to the lexical concepts in question, rather than from a top-down process of overarching conceptual metaphor.

Claim 3: conceptual metaphors and semantic affordances provide two, complementary knowledge types essential to figurative language meaning construction. LCCM theory assumes that language use - specifically, figurative conceptions - draws on a number of different knowledge types. These include purely linguistic as well as conceptual knowledge. The semantic dimension of linguistic knowledge is modelled in terms of the theoretical construct of the lexical concept, which constitutes a bundle of different knowledge types (see Evans 2009b for full details). Conceptual knowledge takes different forms, including - at the very least - primary cognitive models; secondary cognitive models; and conceptual metaphors, which structure primary cognitive models in terms of structure recruited from other domains. Because LCCM theory takes a usage-based perspective, I assume that any utterance, in producing a conception, invokes various knowledge types - including context of use.

Claim 4: in LCCM theory, conceptual metaphors hold at the level of cognitive models. They structure the primary cognitive model(s) to which an open-class lexical concept facilitates access. This means that the cognitive model profile for a lexical concept such as [CHRISTMAS] has enhanced conceptual structure, potentially facilitating access to relational knowledge about the motion of objects through space. This allows language users to invoke inferences, associated with objects in motion, to understand temporal relations involving the relative 'location' in time of a temporal event (here, Christmas). The next section describes how this might work in practice.

\subsection{Interaction between conceptual metaphors and semantic affordances in figurative meaning construction}

In this section, I argue that linguistically mediated figurative meaning often arises due to interaction between conceptual metaphors and semantic affordances. Consider these examples:

(27) a. Christmas is approaching (us).

b. Christmas whizzed by this year.

CMT claims that these sentences are motivated by the conceptual metaphor TIME IS OBJECTS IN MOTION (ALONG A PATH): $a k a$ the Moving Time metaphor. However, while this is, presumably, part of the story - allowing one to conceptualize a temporal event, Christmas, in terms of inferential structure associated with objects and relative locations on a path in terms of temporal notions of past, present, and future - it is not the whole story, and cannot be for the following reason.

While (27a) implies the relative imminence of a temporal event, Christmas, no such inference is provided by (27b) - which, instead, implies that the temporal event was perceived as having a relatively shorter duration than usual: the phenomenon of temporal compression (see Evans 2004, 2009b: Chapter 15). These inferences are independent of the Moving Time conceptual metaphor. 
They must be, because these inferences arise when [APPROACHING] and [WHIZZ (BY)] are deployed in veridically spatial rather than temporal scenarios:

(28) a. The woman is approaching.

b. The car whizzed by.

The inference in (28a) is that the woman's arrival is imminent. Analogously, (28b) provides the inference that the perceptual awareness of the car was experienced for a relatively short time. These semantic affordances arise automatically as a consequence of the cognitive model profile to which the lexical concepts [APPROACHING] and [WHIZZ] facilitate access. They combine with the Moving Time metaphor in (27a) and (27b) to give rise to figurative meaning. Below, I sketch how the Moving Time conceptual metaphor is accessed by the [CHRISTMAS] lexical concept to construct a figurative conception of (27a).

The lexical concept [CHRISTMAS] facilitates access to a number of primary cognitive models, as Figure 2 illustrates. One knowledge type relates to Christmas as a CULTURAL FESTIVAL that includes the exchange of gifts among other cultural practices. Another relates to Christmas as a TEMPORAL EVENT, which includes a whole host of knowledge associated with the TEMPORAL EVENT cognitive model (see Evans 2009b for detailed discussion). Part of one's knowledge about temporal events is that they can be situated in PAST, PRESENT, or FUTURE. Another part is its DURATION, which has a number of values associated with it. Moving from right to left, the first is TEMPORAL COMPRESSION: the overestimation of time, which is to say the experience that time is proceeding more quickly than usual. The second is SYNCHRONOUS DURATION: the normative estimation of time, which is to say the experience of time unfolding at its cultural and phenomenologically standard or equable rate. The third is PROTRACTED DURATION: underestimation of duration, which is to say the experience that time is proceeding more slowly than usual. The final primary cognitive model in Figure 2 is Christmas as a RELIGIOUS FESTIVAL. This relates to knowledge about the nature of Christmas as a Christian event and the way the festival is enacted and celebrated.

The primary cognitive models for [CHRISTMAS] recruit structure from other cognitive models via conceptual metaphor. As LCCM theory operationalizes, a conceptual metaphor provides a stable link allowing aspects of conceptual content, encoded by one cognitive model, to be imported to form part of the permanent knowledge representation encoded by another.

For instance, the primary cognitive model TEMPORAL EVENT is structured via conceptual metaphor in terms of a stable, long-term link between it and the cognitive model relating to an OBJECT IN MOTION ALONG A PATH. That cognitive model - represented in Figure 2 as a circle along a path, with the arrow indicating direction of motion - provides the TEMPORAL EVENT cognitive model with relational structure concerning knowledge of objects undergoing motion along a path. The conceptual content recruited via conceptual metaphor is indicated by the dashed lines. 


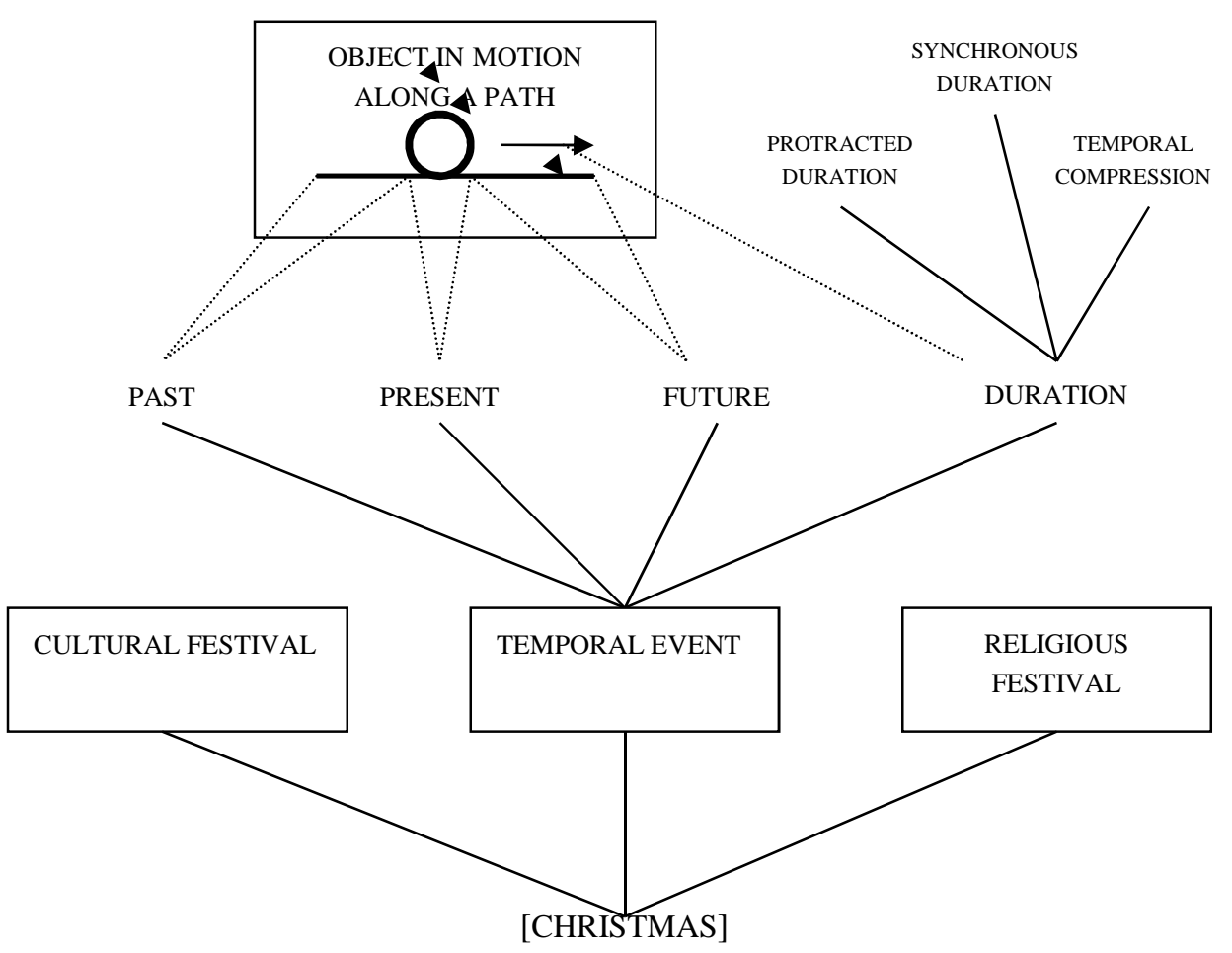

Figure 2: Partial primary cognitive model profile for [CHRISTMAS].

Relational structure from this cognitive model is inherited by the PAST, PRESENT, and FUTURE attributes, such that content, relating to the region of the path behind the object, serves in part to structure one's experience of 'pastness'; content, relating to the object's present location, serves in part to structure one's experience of the present; and content, relating to that portion of the path in front of the object, serves to structure one's experience of the future. This is indicated by the dashed lines, which map the relevant portions of the path of motion from the OBJECT IN MOTION ALONG A PATH cognitive model onto the attributes FUTURE, PRESENT, and PAST. Content relating to the nature of motion is inherited by the DURATION attribute. This is captured by another dashed line, which links the arrow - signifying motion - with the DURATION attribute.

It is now possible to see how a sentence such as (27a) is understood to relate to a temporal event (Christmas) 'located' in the future. This inference arises due to matching between the primary cognitive model of [CHRISTMAS] - involving spatial content recruited via conceptual metaphor - and the primary cognitive model profile accessed via [APPROACHING]. See Figure 3. The conceptual metaphor structures the primary cognitive model TEMPORAL EVENT, providing it with relational structure recruited from a cognitive relation to motion through space.

In this case, matching is achieved in the primary cognitive model profiles of both [CHRISTMAS] and [APPROACHING]. Through conceptual metaphor, [CHRISTMAS] facilitates access to relational structure derived from the scenario of an object in motion: knowledge that forms part of the TEMPORAL EVENT cognitive model. This is matched with the kind of terminal motion accessed via 
[APPROACHING]. The cognitive model profile associated with [APPROACHING] involves motion towards an entity: the object in motion is in front of the entity it is 'approaching'. Because the FUTURE attribute of the TEMPORAL EVENT cognitive model accessed via [CHRISTMAS] is structured in terms of that part of the motion trajectory that is in front, there is a match. That match involves interpreting the temporal event of Christmas as 'located' in the future. This interpretation is a consequence of a special type of matching I refer to as conceptual metaphor matching.

LCCM theory assumes that, in cases of conceptual metaphor matching, regular matching still takes place. In other words, conceptual metaphor matching involving primary cognitive models does not prohibit additional figurative semantic affordances arising via activation in the secondary cognitive profile of one of the lexical concepts undergoing matching and clash resolution.

The second issue to account for in (27a) concerns the inference that the temporal event of Christmas is relatively imminent. I argue that this interpretation arises due to additional matching in the secondary cognitive model profile of [APPROACHING]. Again, just because conceptual metaphor matching has occurred does not preclude further matching. This secondary process attempts to construct an interpretation for [CHRISTMAS] and [APPROACHING] by first searching the primary cognitive models of both these open-class lexical concepts. Christmas is a temporal, cultural, and religious event, and hence something that cannot undergo the sort of veridical motion implicated by the primary cognitive model profile associated with [APPROACHING]. A clash arises, necessitating resolution ${ }^{14}$ via a search in the secondary cognitive model profile of [APPROACHING].

Figure 3 provides a very partial cognitive model for [APPROACHING], including primary cognitive models for TARGET LOCATION, DIRECTED MOTION OF AN ENTITY, and THE IMMINENCE OF ARRIVAL OF AN ENTITY. A consequence of the latter is IMMINENCE OF OCCURRENCE OF EVENT: a secondary cognitive model. A temporal event such as Christmas can occur but not (literally) arrive, so there is a match between the secondary cognitive model IMMINENCE OF OCCURRENCE OF EVENT and the primary cognitive model profile of [CHRISTMAS]. The interpretation of the imminence of the occurrence of Christmas is due to a semantic affordance arising from clash resolution following regular matching.

This analysis reveals that interpretation of (27a) involves more than simply conceptual metaphor. A number of different knowledge types are involved; regular processes of meaning construction take place, as modelled by LCCM theory. This involves understanding the temporal event as an object that can undergo motion - via conceptual metaphor - and, hence, be 'located' in the future. It further requires understanding - through clash resolution - that the type of motion implicates the relative imminence of occurrence. This is achieved without recourse to conceptual metaphor, via semantic affordance.

\footnotetext{
${ }^{14}$ For details of when clash resolution arises and other factors that bear on figurative meaning construction, see (Evans 2010b).
} 


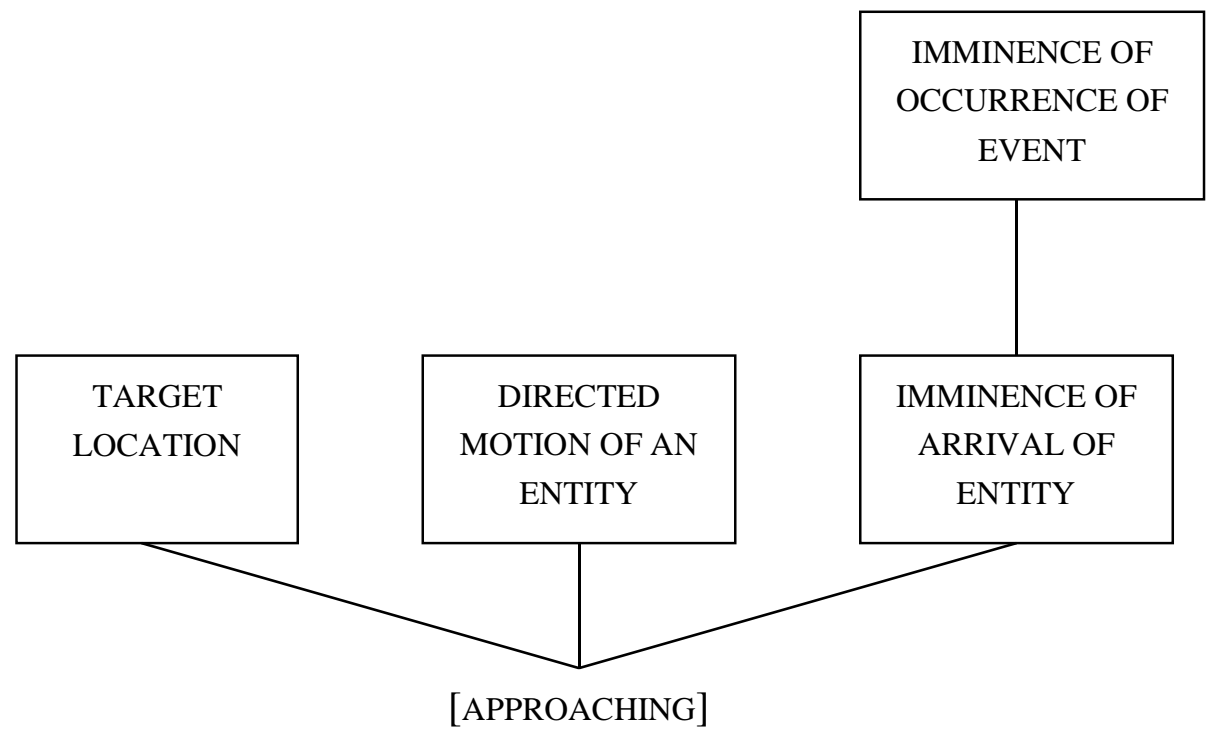

Figure 3: Partial cognitive model profile for [APPROACHING].

\section{CONCLUSION}

In this paper, I have argued that, while it is an important theoretical construct, conceptual metaphor is but one type of knowledge unit playing a role in figurative meaning construction. In particular, I have argued that, while conceptual metaphors inhere in the conceptual system, a class of metaphors discourse metaphors - emerge and evolve in and through language use; they inhere in the linguistic system. I refer to the semantic units associated with words and other linguistic expressions as lexical concepts. I introduce LCCM theory and suggest that lexical concepts provide access to non-linguistic knowledge representations - cognitive models - that can be structured in terms of conceptual metaphor. The integration of lexical concepts in figurative meaning construction gives rise to the integration of conceptual metaphor with other types of conceptual knowledge: most notably, semantic affordances. The combination of these two types of knowledge representation facilitates the figurative meaning construction in the examples I have considered, rather than conceptual metaphor alone. This perspective promises to build towards a joined-up account of figurative meaning construction.

\section{REFERENCES}

Allwood, J. (2003). Meaning potential and context. In Cuyckens, H., Dirven, R. \& Taylor, J. (eds). Cognitive Approaches to Lexical Semantics (29-65). Mouton de Gruyter.

Barsalou, L. (1999). Perceptual symbol systems. Behavioral and Brain Sciences, 22: 577-660.

Barsalou, L. (2005). Continuity of the conceptual system across species. Trends in Cognitive Sciences, 9: 309-311.

Barsalou, L. (2008). Grounded cognition. Annual Review of Psychology, 59: 617-645. 
Black, M. (1979). More about metaphor. In Ortony, A. (ed.). Metaphor and Thought (19-42). Cambridge, UK: Cambridge University Press.

Blank, G.D. (1988). Metaphors in the lexicon. Metaphor and Symbolic Activity, 3: 21-36.

Bowdle, B. \& Gentner, D. (2005). The career of metaphor. Psychological Review, 112: 193-216.

Boroditsky, L. (2000). Metaphoric structuring: Understanding time through spatial metaphors. Cognition, 75(1): 1-28.

Bybee, J., Perkins, R. \& Pagluica, W. (1994). The Evolution of Grammar: Tense, Aspect and Modality in the Languages of the World. Chicago: University of Chicago Press.

Casasanto, D. \& L. Boroditsky. (2008). Time in the mind: Using space to think about time. Cognition, 106: 579-593.

Chatterjee, A. (2010). Disembodying cognition. Language and Cognition, 2(1): 79-116.

Coulson, S. (2000). Semantic Leaps. Cambridge, UK: Cambridge University Press.

Coulson, S. (2008). Metaphor comprehension and the brain. In Gibbs, R. (ed.), The Cambridge Handbook of Metaphor and Thought (177-196). Cambridge, UK: Cambridge University Press.

Evans, N. \& Wilkins, D. (2000). In the mind's ear: The semantic extensions of perception verbs in Australian languages. Language, 76(3): 546-592.

Evans, V. (2004). The Structure of Time: Language, Meaning and Temporal Cognition. Amsterdam: John Benjamins.

Evans, V. (2006). Lexical concepts, cognitive models and meaning-construction. Cognitive Linguistics 17(4): 491-534.

Evans, V. (2007). Towards a Cognitive Compositional Semantics. In Magnusson, U., Kardela, H. \& Glaz, A. (eds.), Further Insights in Semantics and Lexicography (11-42). Lublin, Poland: University Marie Curie University Press.

Evans, V. (2009a). Semantic representation in LCCM theory. In Evans, V. \& Pourcel, S. (eds.), New Directions in Cognitive Linguistics (27-55). Amsterdam: John Benjamins.

Evans, V. (2009b). How Words Mean: Lexical Concepts, Cognitive Models and Meaning Construction. Oxford: Oxford University Press.

Evans, V. (2010a). From the spatial to the non-spatial: The 'state' lexical concepts of in, on and at. In Evans, V. \& Chilton, P. (eds.), Language, Cognition and Space: The State of the Art and New Directions (215-248). London: Equinox Publishing.

Evans, V. (2010b). Figurative language understanding in LCCM theory. Cognitive Linguistics, 21(4): 601-662.

Evans, V. (2013). Language and Time. Cambridge, UK: Cambridge University Press.

Fauconnier, G. \& Turner, M. (2002). The Way We Think: Conceptual Blending and the Mind's Hidden Complexities. New York: Basic Books.

Fauconnier, G. \& Turner, M. (2008). Rethinking metaphor. In Gibbs, R. (ed.), The Cambridge Handbook of Metaphor and Thought (53-66). Cambridge, UK: Cambridge University Press. 
Gallese, V. \& Lakoff, G. (2005). The brain's concepts: The role of the sensory-motor system in reason and language. Cognitive Neuropsychology, 22: 455-479.

Gentner, D. (1983). Structure-mapping: A theoretical framework for analogy. Cognitive Science, 7: 155-170.

Gentner, D., Bowdle, B., Wolff, P. \& Boronat, C. (2001). Metaphor is like analogy. In Gentner, D., Holyoak, K.J. \& Kokinov, B. (eds.), The Analogical Mind: Perspectives from Cognitive Science (199-253). Cambridge, MA, USA: MIT Press.

Gentner, D., Imai, M. \& Boroditsky, L. (2002). As time goes by: Evidence for two systems in processing space time metaphors. Language and Cognitive Processes, 17(5): 537-565.

Gentner, D., \& Wolff, P. (1997). Alignment in the processing of metaphor. Journal of Memory and Language, 37: 331-355.

Giora, R. (2008). Is metaphor unique? In Gibbs, R. (ed.), The Cambridge Handbook of Metaphor and Thought (143-160). Cambridge, UK: Cambridge University Press.

Glenberg, A. (1997). What memory is for. Behavioral and Brain Sciences, 20: 1-55.

Glenberg, A. \& Kaschak, M. (2002). Grounding language in action. Psychonomic Bulletin and Review, 9: 558-565.

Glucksberg, S. (2001). Understanding Figurative Language: From Metaphors to Idioms. Oxford: Oxford University Press.

Glucksberg S. \& Keysar, B. (1990). Understanding metaphorical comparisons: Beyond similarity, Psychological Review, 97: 3-18.

Grady, J. (1997a). THEORIES ARE BUILDINGS revisited. Cognitive Linguistics, 8(4): 267-290.

Grady, J. (1997b). Foundations of Meaning: Primary Metaphors and Primary Scenes. Unpublished doctoral thesis, department of linguistics, University of California at Berkeley.

Grady, J. (1999). A typology of motivation for conceptual metaphor: Correlation vs. resemblance. In Gibbs, R., Jr. \& Steen, G. (eds.), Metaphor in Cognitive Linguistics: Selected Papers from the Fifth International Cognitive Linguistics Conference, Amsterdam 1997 (79-100). Amsterdam: John Benjamins.

Grady, J. (2005). Primary metaphors as inputs to conceptual integration. Journal of Pragmatics, 37: 1595-1614.

Heine, B., Claudi, U. \& Hünnemeyer, F. (1991). Grammaticalization: A Conceptual Framework. Chicago: University of Chicago Press.

Heine, B. \& Kuteva, T. (2007). The Genesis of Grammar. Oxford: Oxford University Press.

Hurford, J. (2007). Origins of Meaning. Oxford: Oxford University Press.

Johnson, M. \& Malgady, R. (1979). Some cognitive aspects of figurative language: Association and metaphor. Journal of Psycholinguistic Research, 8: 249-265.

Kaschak, M. \& Glenberg, A. (2000). Constructing meaning: The role of affordances and grammatical constructions in sentence comprehension. Journal of Memory and Language, 43: 508-529. 
Lakoff, G. (1987). Women, Fire and Dangerous Things: What Categories Reveal about the Mind. Chicago: Chicago University Press.

Lakoff, G. (1993). The contemporary theory of metaphor. In Ortony, A. (ed.), Metaphor and Thought: Second Edition (202-251). Cambridge: Cambridge University Press.

Lakoff, G. (2008). The neural theory of metaphor. In Gibbs, R. (ed.), The Cambridge Handbook of Metaphor and Thought (17-38). Cambridge, UK: Cambridge University Press.

Lakoff, G. \& Johnson, M. (1980). Metaphors We Live By. Chicago: University of Chicago Press.

Lakoff, G. \& Johnson, M. (1999). Philosophy in the Flesh. New York: Basic Books.

Lakoff, G. \& Turner, M. (1989). More than Cool Reason. Chicago: University of Chicago Press.

Langacker, R.W. (1987). Foundations of Cognitive Grammar: Vol. I. Stanford, CA, USA: Stanford University Press.

Malgady, R., \& Johnson, M. (1976). Modifiers in metaphors: Effects of constituent phrase similarity on the interpretation of figurative sentences. Journal of Psycholinguistic Research, 5: 43-52.

Mandler, J. (2010). The spatial foundations of the conceptual system. Language and Cognition, 2(1): 21-44.

Marschark, M., Katz, A. \& Paivio, A. (1983). Dimensions of metaphor. Journal of Psycholinguistic Research, 12: 17-40.

McGlone, M \& Harding, J. (1998). Back (or forward?) to the future: The role of perspective in temporal language comprehension. Journal of Experimental Psychology: Learning, Memory, and Cognition, 24: 1211-1223.

Miller, G. (1979). Images and models, similes and metaphors. In Ortony, A. (ed.), Metaphor and Thought (202-250). Cambridge, UK: Cambridge University Press.

Moore, K.E. (2006). Space-to-time mappings and temporal concepts. Cognitive Linguistics, 17(2): 199-244.

Núñez, R., Motz, B. \& Teuscher, U. (2006). Time after time: The psychological reality of the ego- and time-reference-point distinction in metaphorical construals of time. Metaphor and Symbol, 21: 133-146.

Ortony, A. (1979). Beyond literal similarity. Psychological Review, 86: 161-180.

Pulvermüller, F. (2003). The Neuroscience of Language: On Brain Circuits of Words and Serial Order. Cambridge, UK: Cambridge University Press.

Shapiro, L. (2010). Embodied Cognition. London: Routledge.

Sweetser, E. (1988). Grammaticalization and semantic bleaching. In Axmaker, S, Jaisser, A. \& Singmaster H., Berkeley Linguistics Society Proceedings of the Fourteenth Annual Meeting (389405), Berkeley, CA, USA: Berkeley Linguistics Society.

Sweetser, E. (1990). From Etymology to Pragmatics: Metaphorical and Cultural Aspects of Semantic Structure. Cambridge, UK: Cambridge University Press. 
Taylor, L. \& Zwaan, R. (2009). Action in cognition: The case of language. Language and Cognition, 1(1): 45-58.

Traugott, E.C. (1989). On the rise of epistemic meanings in English: An example of subjectification in semantic change. Language, 58: 33-65.

Traugott, E.C. \& Dasher, R. (2004). Regularity in semantic change. Cambridge, UK: Cambridge University Press.

Tversky, A. (1977). Features of similarity. Psychological Review, 84: 327-352.

Tyler, A. \& Evans, V. (2001). Reconsidering prepositional polysemy networks: The case of over. Language, 77(4): 724-765.

Tyler, A. \& Evans, V. (2003). The Semantics of English Prepositions: Spatial Scenes, Embodied Meaning and Cognition. Cambridge, UK: Cambridge University Press.

Vigliocco, G., Meteyard, L., Andrews, M. \& Kousta, S. (2009). Toward a theory of semantic representation. Language and Cognition, 1(2): 219-248.

Zinken, J. (2007). Discourse metaphors: The link between figurative language and habitual analogies. Cognitive Linguistics, 18(3): 445-466.

Zlatev, J. (2011). From cognitive to integral linguistics and back again. Intellectica, 56: 125-147.

Zwaan, R. (2004). The immersed experiencer: Toward an embodied theory of language comprehension. In Ross, B .H. (ed.), The Psychology of Learning and Motivation (35-62). New York: Academic Press. 